Check for updates

Cite this: RSC Adv., 2018, 8, 32545

Received 23rd June 2018

Accepted 20th August 2018

DOI: $10.1039 / c 8 r a 05395 b$

rsc.li/rsc-advances

\section{Adsorption of methylene blue and tetracycline onto biomass-based material prepared by sulfuric acid reflux $\dagger$}

\author{
Md. Tariqul Islam, (D) *ab Ricardo Saenz-Arana, ${ }^{a}$ Cesar Hernandez, ${ }^{a}$ Thomas Guinto, ${ }^{a}$ \\ Md Ariful Ahsan, ${ }^{a}$ Hoejin Kim, ${ }^{c}$ Yirong Lin, ${ }^{c}$ Bonifacio Alvarado-Tenorio ${ }^{d}$ \\ and Juan C. Noveron*ab
}

The adsorptive removal of environmental pollutants is an effective method for the treatment of contaminated water. Thus, the preparation of adsorbents from low-cost, readily available, and renewable resources has garnered immense attention in recent years. In this study, a facile one-step method for the preparation of a high-capacity adsorbent is demonstrated by refluxing pine cones in concentrated sulfuric acid. With sulfuric acid reflux, the pine cones undergone carbonization as well as functionalization with sulfonic acid groups. The adsorbent demonstrated high adsorption capacity for two emerging organic pollutants, methylene blue (MB) and tetracycline (TC). Different variables such as $\mathrm{pH}$, temperature, contact time, and initial concentration of the pollutants were analyzed and showed that the adsorption capacity for MB increased in a basic $\mathrm{pH}$ and vice versa for TC. Also, the elevated temperature favored the adsorption for both MB and TC. The maximum adsorption capacity was found to be 1666.66 , and $357.14 \mathrm{mg} \mathrm{g}^{-1}$ for MB and $\mathrm{TC}$, respectively. In comparison to the pristine pine cone, the sulfuric acid treated pine cone demonstrated an extraordinary improvement in the adsorption capacity. The adsorption of MB and TC was performed from the tap water matrix and similar adsorption capacities were found. A packed glass column was also prepared to demonstrate the adsorption of MB from tap water under flow conditions.

\section{Introduction}

Biomass conversion into fuels and commodity products has attracted considerable attention due to the large range of benefits of environmental sustainability. ${ }^{\mathbf{1} 2}$ Although there has been an emphasis on the conversion of biomass to biofuels, ${ }^{3}$ the development of new methods to generate bio-derived products such as bio-plastics, ${ }^{4}$ bio-oils, ${ }^{5}$ biogas, ${ }^{6}$ bio-molecules, ${ }^{7}$ bio-char ${ }^{8}$ and most recently bio-carbon products has been increasing. ${ }^{9}$ Along the same lines, bio-derived adsorbents have attracted significant

${ }^{a}$ Department of Chemistry, University of Texas, El Paso, 500 West University Avenue, El Paso, Texas 79968, USA.E-mail: jcnoveron@utep.edu; mtislam@miners.utep.edu; tariqul.lab@gmail.com

${ }^{b}$ Nanosystems Engineering Research Center for Nanotechnology-Enabled Water Treatment, USA

'Department of Mechanical Engineering, University of Texas, El Paso, 500 West University Avenue, El Paso, Texas 79968, USA

${ }^{d}$ Instituto de Ciencias Biomédicas, Universidad Autónoma de Ciudad Juárez, Ciudad Juárez, Chihuahua, Mexico

$\uparrow$ Electronic supplementary information (ESI) available: UV-visible spectrum of the MB and TC solutions in water. The calibration curves of MB and TC. Linear form of the Freundlich isotherm model of adsorption, pseudo-first order kinetic model of adsorption, adsorption capacity of the unmodified pine cone for MB and TC, and list of different species present in the tap water. See DOI: 10.1039/c8ra05395b attention because they can provide an environmentally friendly and sustainable way to remove pollutants from wastewater. ${ }^{\mathbf{1 0 , 1 1}}$ For example, modified and unmodified biomass derived adsorbents, such as dead biomass, living plants, fungi, bacteria, algae, yeast, waste sludge, agricultural wastes, biochar and activated carbon/charcoal, are widely utilized for the adsorption of organic and heavy metal pollutants from water. ${ }^{\mathbf{1 2 - 1 5}}$ Because biomass is low-cost, highly abundant, and renewable; it has the advantage of being economically feasible to low-resource areas and thereby the biomass conversion into adsorbents has garnered immense attention in recent years. ${ }^{16,17}$ The utilization of biomass-derived adsorbents for the remediation of environmental pollutants from water can provide the access of clean water to rural and urban areas.

The rapid growth of population and increased industrialization are leading to the scarcity of water in many sectors. ${ }^{18}$ In the clean water sector, water contamination with organic compounds and heavy metals is becoming a serious health concern in both rural and urban areas. Therefore, clean water is becoming increasingly scarce almost everywhere in the world. ${ }^{19}$ For example, organic dyes are used in a variety of important industries, including but not limited to: textile, paper, paint, plastic, leather, food, cosmetic, and pharmaceuticals. ${ }^{20}$ In the textile industry, it is estimated that every year up to 20000 tons of these dyes are lost in the process and end up in fresh water bodies. ${ }^{21}$ These untreated wastewaters 
synergistically pollute the usable freshwater supply. According to a report published by the US-EPA, many of these dyes are toxic and potential carcinogens to humans, which make their presence in the water a major health hazard. ${ }^{22}$ In addition to organic dyes, antibiotics have also become emerging water pollutants. Because of their improper disposal from hospitals, cattle and poultry industries; they are posing a new type of threat to the environment, as well as human health. The presence of antibiotics in the environment is not only unexpected, but also leads to the gradual increase in bacterial resistance. Therefore, the removal of antibiotics, like other pollutants, has become an essential part of wastewater treatment. ${ }^{23}$

Many different physical (adsorption, ultrafiltration, etc.), ${ }^{24,25}$ chemical catalytic (reduction, oxidation), ${ }^{26-28}$ photocatalytic, ${ }^{29,30}$ and electrocatalytic, ${ }^{31}$ and biological ${ }^{32}$ methods have been employed to remove or degrade the organic dyes and antibiotics. However, many of these methods are prohibitively costly, produce secondary chemical waste or are not effective enough to be applicable. In this regard, the adsorptive removal of pollutants from contaminated water has gained much attention, as the process is simple, less energy consuming, and does not cause secondary pollution. ${ }^{33}$ Commonly used adsorbents, such as activated carbon and ion exchange resins, are difficult to produce and thereby expensive in regards to the utilization in low-resource areas. ${ }^{34}$ Hence, the development of adsorbents from cheap and renewable sources, such as biomass, has become an intriguing alternative solution for the resourcelimited areas.

Herein, we report a simple and scalable method for the preparation of a sulfonic acid functionalized carbonaceous adsorbent derived from pine cone for the removal of methylene blue and tetracycline from water. Pine cone is used because it is one of the widely available biomasses that has no such economical values. Additionally, as pine is a hard-wood type tree the fruit (pine cone) has a high percentage lignin. ${ }^{35}$ The lignin consists of aromatic rings and thereby can be simultaneously carbonized and functionalized to sulfonic acid group by the sulfuric acid reflux. The adsorbent was chemically and physically characterized by Fourier Transform Infrared Spectroscopy (FTIR), Thermogravimetric Analysis (TGA), Scanning Electron Microscopy (SEM), X-ray Powder Diffraction (XRPD), Energy Dispersive X-ray Scattering (EDS), X-ray Photoelectron Spectroscopy (XPS), and Raman spectroscopy. The FTIR, XRPD, EDS, XPS, and the Raman spectroscopy revealed the presence of sulfonic acid group and the carbonaceous nature whereas the SEM end TGA analyses demonstrated the morphology and thermal stability of the adsorbent, respectively. The sulfonated pinecone $\left(\mathrm{PC}^{\left.-\mathrm{SO}_{3} \mathrm{H}\right)}\right.$ was utilized for the adsorptive removal of $\mathrm{MB}$ and TC from water. The adsorption kinetics, isotherms, and thermodynamics were systematically studied and compared with the existing reports.

\section{Materials and methods}

\subsection{Materials}

Dry and mature pine cone was obtained from a local pine tree (El Paso, Texas) and was used without any further treatment.
Concentrated sulfuric acid (95-98\%), sodium hydroxide (>97\%), were purchased from BDH Chemicals. Methylene blue (>98\%) and tetracycline $(\geq 98 \%$ ) were purchased from Consolidated Chemical and Sigma Aldrich, respectively. Coarse sand was purchased from J. T. Baker (CAS number: 14808-60-7, MDL no. MFCD02100519). Ultrasonic bath sonicator (VWR 50T), having frequency of $60 \mathrm{~Hz}$, was used to homogenize the adsorption mixture. Deionized water with a resistance of about $18.2 \mathrm{M} \Omega \mathrm{cm}$ at $25^{\circ} \mathrm{C}$ was obtained from Milli-Q water purifier facilities (EMD Millipore Corporation) from the lab. Tap water was obtained from the regular water faucet of the lab. The complete list of the soluble and insoluble species of the tap water is given in ESI, Fig. S1. $\dagger$

\subsection{Preparation of the adsorbent}

The preparation of sulfuric acid treated PC is depicted in Scheme 1. In detail, in a $300 \mathrm{~mL}$ round bottomed flask, $10 \mathrm{~g}$ of the unseeded and cut PC was mixed with $40 \mathrm{~mL}$ of concentrated $\mathrm{H}_{2} \mathrm{SO}_{4}$ (95-98\%). An excess of $\mathrm{H}_{2} \mathrm{SO}_{4}$ was used to have a good suspension to ensure the reaction could be stirred properly during reflux. The reaction was refluxed in boiling $\mathrm{H}_{2} \mathrm{SO}_{4}$ for $3 \mathrm{~h}$ while stirring. After the reflux ended, the product mixture was cooled to room temperature, and $250 \mathrm{~mL}$ of cold water was slowly added to the mixture, with care so that the mixture didn't overheat or become volatile. Once the reflux finished, the reaction mixture was cooled down to room temperature and $250 \mathrm{~mL}$ of ice-cold water was slowly added to the mixture with due precautions.

Once the mixture was diluted, it was vacuum filtered and washed with about $3 \mathrm{~L}$ of DI water to remove the excess $\mathrm{H}_{2} \mathrm{SO}_{4}$. The sulfonated pine cone $\left(\mathrm{PC}-\mathrm{SO}_{3} \mathrm{H}\right)$ was dried by placing it in a vacuum oven at $110{ }^{\circ} \mathrm{C}$ for $12 \mathrm{~h}$. After the adsorbent had fully dried, it was ground to a fine powder with a ceramic mortar and pestle. The amount of $\mathrm{PC}-\mathrm{SO}_{3} \mathrm{H}$ recovered was about $5.6 \mathrm{~g}$.

\subsection{Batch adsorption experiments}

For the batch adsorption experiments of TC and $\mathrm{MB}$, in a $25 \mathrm{~mL}$ glass vial, $20 \mathrm{mg}$ of the $\mathrm{PC}-\mathrm{SO}_{3} \mathrm{H}$ was added to a $20 \mathrm{~mL}$ solution of TC and $\mathrm{MB}$, having initial concentrations varying from 300 to $2000 \mathrm{ppm}$ for $\mathrm{MB}$, and 50 to $500 \mathrm{ppm}$ for TC. The mixture was then bath sonicated for $30 \mathrm{~min}$, and then stirred at $1000 \mathrm{rpm}$ on a magnetic stirrer for a period of $24 \mathrm{~h}$. It was found that adsorption reached equilibrium after a period of $24 \mathrm{~h}$ and thereby a stirring period of $24 \mathrm{~h}$ was used for all the equilibrium adsorption experiments. After $24 \mathrm{~h}$ of stirring, $1 \mathrm{~mL}$ of the mixture was filtered through a $0.25 \mu \mathrm{m}$ PTFE syringe filter to obtain a clear filtrate. The adsorption capacity was calculated
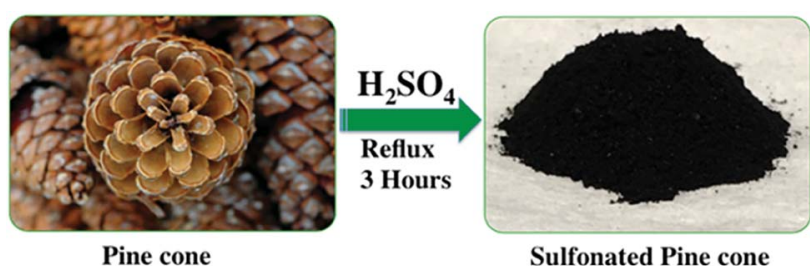

Sulfonated Pine cone

Scheme 1 Preparation of sulfonated pine cone $\left(\mathrm{PC}-\mathrm{SO}_{3} \mathrm{H}\right)$. 
from the difference between the initial and final concentration of MB and TC, which was obtained by using UV-vis spectrophotometer. The concentration of the TC and MB was obtained from their absorbance at $357 \mathrm{~nm}$ and $615 \mathrm{~nm}$, respectively. The UV-vis spectrum and the calibration curves of MB and TC is given in Fig. S2.†

The $\mathrm{pH}$-dependent adsorption of $\mathrm{MB}$ and $\mathrm{TC}$ was performed

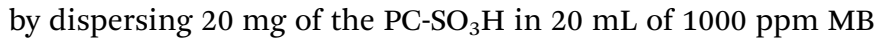
and $200 \mathrm{ppm}$ TC solutions, respectively. The $\mathrm{pH}$ of the solution was adjusted by using $1 \mathrm{M} \mathrm{NaOH}$ and $1 \mathrm{M} \mathrm{HCl}$.

The time-dependent adsorption tests was obtained by adding $40 \mathrm{mg}$ of the $\mathrm{PC}-\mathrm{SO}_{3} \mathrm{H}$ in $40 \mathrm{~mL}$ of $500 \mathrm{ppm} \mathrm{MB}$ and $50 \mathrm{ppm}$ TC solutions at $\mathrm{pH} \sim 7$ and $\sim 3.5$, respectively. Acidic $\mathrm{pH}(\sim 3.5)$ for $\mathrm{TC}$ and neutral $\mathrm{pH}$ for $\mathrm{MB}$ was chosen as it was found that the adsorption of TC and MB was favored in those $\mathrm{pH}$ values. Bath sonication was carried out for $30 \mathrm{~min}$ and while sonication samples $(\sim 0.5 \mathrm{~mL})$ were taken at every $10 \mathrm{~min}$ interval. After the bath sonication, the mixture was stirred continuously on a magnetic stirring plate at $1000 \mathrm{rpm}$ and during which samples were taken at every $30 \mathrm{~min}$ interval.

The temperature-dependent adsorptions were performed using $20 \mathrm{mg}$ of the adsorbent in $20 \mathrm{~mL}$ of the $\mathrm{MB}$ and $\mathrm{TC}$ solutions at 23,40 , and $60{ }^{\circ} \mathrm{C}$. Initial concentrations ranging from 300 to $600 \mathrm{ppm}$ for $\mathrm{MB}$ and 200 to $400 \mathrm{ppm}$ for TC were chosen for the adsorption of MB and TC. It was found that at 40 and $60{ }^{\circ} \mathrm{C}$, TC undergone thermal degradation and thereby the absorbance at $357 \mathrm{~nm}$ dropped to some extent. Therefore, for the calculation of adsorption capacity at elevated temperatures, the amount of natural degradation was subtracted. However, no natural degradation of $\mathrm{MB}$ was found either at room temperature or at elevated temperatures.

\subsection{Preparation of the adsorption column}

A fritted chromatographic column with reservoir having the dimensions of I.D. $\times L=26 \times 457 \mathrm{~mm}$ was packed to about

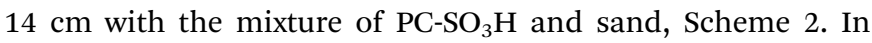
detail, $2 \mathrm{~g}$ of the $\mathrm{PC}-\mathrm{SO}_{3} \mathrm{H}$ was homogeneously mixed with $110 \mathrm{~g}$ of sea sand by a ceramic mortar and pestle for few minutes of gentle grinding. Afterwards, the column was filled by the dry filling method. To help disperse the flow as well as to prevent the leakage of any absorbent, cotton and coarse sea sand were used at the bottom and the top of the column, respectively.

The column was initially washed with $100 \mathrm{~mL}$ of DI water then a $20 \mathrm{ppm} \mathrm{MB}$ solution was prepared in tap water without the adjustments of the $\mathrm{pH}$. However, it was found that the solution $\mathrm{pH}$ was about 7 . The solution was fed into the column and allowed to flow through the filter under gravity. The flow rate varied from 6 to $6.8 \mathrm{~mL} \mathrm{~min}^{-1}$. For every $1000 \mathrm{~mL}$ of solution filtered, $2 \mathrm{~mL}$ of filtrate was sampled for UV-vis analysis. The filtration was continued until trace of MB was detected in the filtrate by naked eye observation.

\subsection{Adsorption isotherms and kinetics}

The experimental adsorption results were analyzed by utilizing the linear form of the Langmuir and Freundlich isotherm models, whereas time-dependent adsorption results were

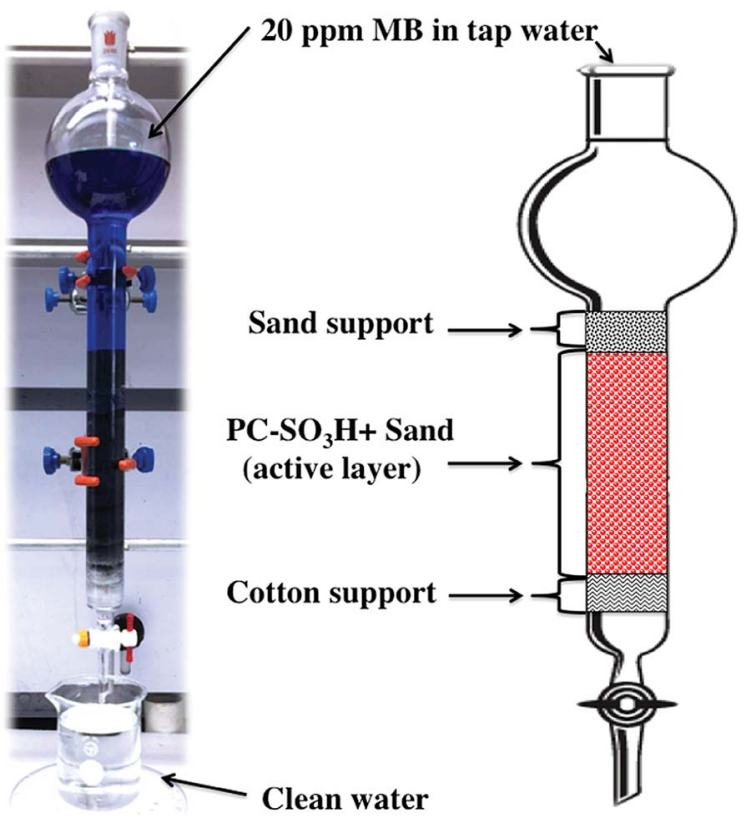

Scheme 2 Design of the column filter packed with $\mathrm{PC}-\mathrm{SO}_{3} \mathrm{H}$ and sand for the continuous adsorption of MB.

analyzed by utilizing the linear form of the pseudo-first and pseudo-second kinetic models. The model isotherms, such as the Langmuir and Freundlich isotherms, give important information about the adsorption processes. For example, the Langmuir isotherm is based on the monolayer type adsorption of molecules on the adsorbent. It is based on the assumption that the adsorption energy of each adsorbate molecule is the same and independent of the surface of the adsorbent. It also assumes that all sites on the adsorbent surface are equivalent and there are no interactions between the adsorbate molecules. The Freundlich model isotherm, on the other hand, is based the assumption that the adsorption of molecules happens both by the monolayer and multilayer on the adsorbent.

The linear form of the Langmuir and Freundlich adsorption isotherm models are expressed by the following equations. ${ }^{36,37}$

$$
\begin{gathered}
\frac{C_{\mathrm{e}}}{Q_{\mathrm{e}}}=\frac{1}{Q_{\mathrm{m}}} C_{\mathrm{e}}+\frac{1}{K_{\mathrm{L}} Q_{\mathrm{m}}} \\
\ln Q_{\mathrm{e}}=\frac{1}{n} \ln C_{\mathrm{e}}+\ln K_{\mathrm{F}}
\end{gathered}
$$

where $C_{\mathrm{e}}$ represents the equilibrium concentrations of the adsorbates $\left(\mathrm{mg} \mathrm{L}^{-1}\right), Q_{\mathrm{e}}$ and $Q_{\mathrm{m}}$ represent the equilibrium and maximum adsorption capacities $\left(\mathrm{mg} \mathrm{g}^{-1}\right)$ of the adsorbent, $K_{\mathrm{L}}$ $\left(\mathrm{L} \mathrm{mg}^{-1}\right.$ ) is the Langmuir constant, which is related to the affinity of the binding sites and the free energy of adsorption.

$K_{\mathrm{F}}$ and $n$ are Freundlich constants, determined from the intercept of the plot of $\ln \left(Q_{\mathrm{e}}\right)$ versus $\ln \left(C_{\mathrm{e}}\right)$. The $K_{\mathrm{F}}$ and $1 / n$ are related to adsorption capacity and the adsorption intensity of the system. The magnitude of the term $(1 / n)$ indicates of the favorability of the adsorbent/adsorbate systems.

The linear form of the pseudo-second-order and the pseudofirst-order kinetic models are expressed by the following equation. ${ }^{36,37}$ 


$$
\begin{gathered}
\frac{t}{Q_{t}}=\frac{t}{Q_{\mathrm{e}}}+\frac{1}{K_{2} Q_{\mathrm{e}}} \\
\log \left(Q_{\mathrm{e}}-Q_{t}\right)=\log Q_{\mathrm{e}}-\frac{K_{1} t}{2.303}
\end{gathered}
$$

where $Q_{t}$ represent the adsorption capacities $\left(\mathrm{mg} \mathrm{g}^{-1}\right)$ at time $t$ (min); $K_{1}\left(\min ^{-1}\right)$ and $K_{2}\left[\mathrm{~g}\left(\mathrm{mg}^{-1} \mathrm{~min}^{-1}\right)\right]$ are the pseudo-firstorder and pseudo-second-order rate constants, respectively. The equilibrium and time-dependent adsorption capacities were calculated using the following equations:

$$
\text { Equilibrium adsorption capacity, } Q_{\mathrm{e}}=\frac{C_{0}-C_{\mathrm{e}}}{m} \times V
$$

The \% dye adsorption was calculated using the following equation:

$$
\text { Adsorption }(\%)=\frac{C_{0}-C_{t}}{C_{0}}=\frac{A_{0}-A_{t}}{A_{0}} \times 100 \%
$$

where $C_{0}$, and $C_{t}$ represent the concentrations of the dyes (mg $\mathrm{L}^{-1}$ ) at the beginning and at time $t$, respectively; $A_{0}$ and $A_{t}$ represent the absorbance of the dyes at concentrations $C_{0}$ and $C_{t}$, respectively; $m$ represents the mass of the adsorbent $(\mathrm{g})$ and $V$ represents the volume of dye solution (L).

\section{Results and discussion}

\subsection{Characterization of adsorbent}

The $\mathrm{PC}-\mathrm{SO}_{3} \mathrm{H}$ was chemically and physically characterized by Scanning Electron Microscopy (SEM) imaging, Energy Dispersive X-ray Spectroscopy (EDS), X-ray Photoelectron Spectroscopy (XPS), FTIR and Raman spectroscopy, X-ray Powder Diffraction (XRPD), Thermogravimetric Analysis (TGA), and zeta potential measurements. The morphology and the elemental composition of the PC- $\mathrm{SO}_{3} \mathrm{H}$ were characterized by the SEM and SEMEDX analyses. X-ray Powder Diffraction analysis (XRPD) was used to determine the crystallinity and the carbonaceous nature of the $\mathrm{PC}_{-} \mathrm{SO}_{3} \mathrm{H}$. FTIR and Raman spectroscopies gave further information about the functional groups and the type of carbon

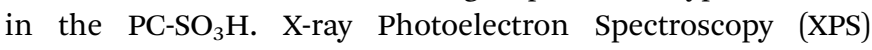
provided the insights about the elemental compositions as well as the type of bonding between different species in the PC$\mathrm{SO}_{3} \mathrm{H}$. The zeta potential analysis provided the net charge of the

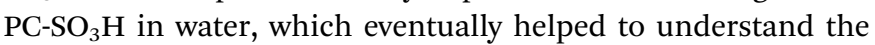
adsorption mechanism by electrostatic interactions. The $\mathrm{N}_{2}$ gas adsorption analysis (BET) was carried out to estimate the specific surface area of the $\mathrm{PC}-\mathrm{SO}_{3} \mathrm{H}$. It was found that the PC$\mathrm{SO}_{3} \mathrm{H}$ had Brunauer-Emmett-Teller (BET) specific surface area of about $4.55 \mathrm{~m}^{2} \mathrm{~g}^{-1}$. In compared to the surface area of the modified and unmodified pine cone, reported in literature, ${ }^{38}$ the specific surface area of the $\mathrm{PC}-\mathrm{SO}_{3} \mathrm{H}$ was found to be higher by several orders of magnitude. Along with the surface functionalization, the higher surface area of the $\mathrm{PC}-\mathrm{SO}_{3} \mathrm{H}$ may be attributed to its exceptionally high adsorption capacity for $\mathrm{MB}$ and TC.

The surface morphology of the $\mathrm{PC}-\mathrm{SO}_{3} \mathrm{H}$ was studied using scanning electron microscope (SEM). The SEM images revealed that the $\mathrm{PC}-\mathrm{SO}_{3} \mathrm{H}$ consists of particles with random size and shape, Fig. 1a and b. The particles were found mostly in the micrometer size range with a large degree of aggregation. The surface of the $\mathrm{PC}_{-} \mathrm{SO}_{3} \mathrm{H}$ was seen rough and uneven without the presence of significant amount of pores.

The SEM coupled with Energy Dispersive X-ray scattering (EDX) provided the qualitative and quantitative elemental analysis of the $\mathrm{PC}-\mathrm{SO}_{3} \mathrm{H}$. The EDX elemental mapping image demonstrated the presence and distribution of sulfur, carbon, and oxygen in the $\mathrm{PC}_{-} \mathrm{SO}_{3} \mathrm{H}$, Fig. $1 \mathrm{c}$ and e. The presence even distribution of carbon, oxygen and sulfur further indicate the presence of $-\mathrm{SO}_{3} \mathrm{H}$ functional group in the adsorbent. The approximate qualitative and quantitative composition of the

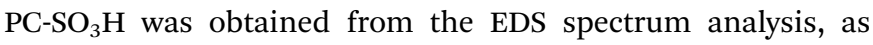
shown in Fig. 2a. According to the EDX analysis, it was observed

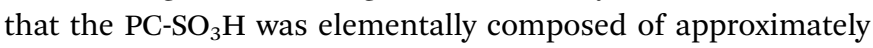
$60.80 \%$ carbon, $34.82 \%$ oxygen, and $4.38 \%$ sulfur by weight.

Raman spectroscopy was used to examine the carbonaceous

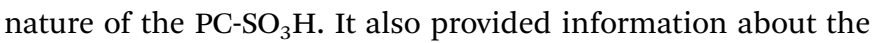

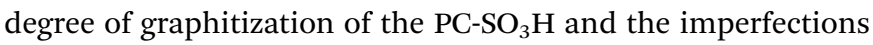

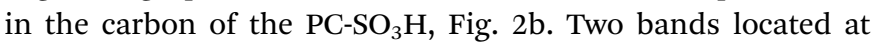
$\sim 1360$ and $1582 \mathrm{~cm}^{-1}$ were observed, which are attributed to the $\mathrm{D}$ and $\mathrm{G}$ bands, respectively. The $\mathrm{D}$ band indicates to the structural defect and disorder and the $\mathrm{G}$ band corresponds to the $\mathrm{sp}^{2}$ carbon network in graphite-like carbon. ${ }^{39,40}$ In addition, the ratio of the intensities of the $\mathrm{G}$ to $\mathrm{D}$ band $\left(I_{\mathrm{D}} / I_{\mathrm{G}}\right)$ is utilized to evaluate the extent of structural disorder for graphite-like

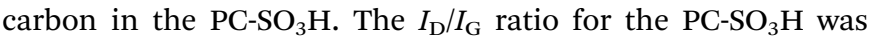
found to be 0.863 , which indicated that the graphite-like carbon in the $\mathrm{PC}^{-\mathrm{SO}_{3} \mathrm{H} \text { has high degree of defects and disorder. }}{ }^{41}$

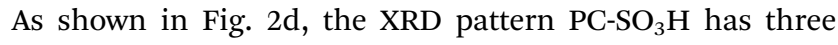
major diffraction peaks at $c a .12 .38,25.73$ and 42.25 . The peaks at 25.38 and 42.25 could be indexed to the (002) and (101) planes of hexagonal graphite (JCPDS no. 41-1487), respectively. ${ }^{42}$ However, the peak at 12.38 could be indexed to the (002) plane of the stacked graphene oxide. ${ }^{43}$ Therefore, it could be considered that the $\mathrm{PC}-\mathrm{SO}_{3} \mathrm{H}$ consists of graphitic as well as graphene oxide like carbons. According to the Bragg's equation $(n \lambda=2 d \sin \theta)$, the inter layer spacing of the 002 and 101 planes of the graphitic carbon of the $\mathrm{PC}-\mathrm{SO}_{3} \mathrm{H}$ was calculated as $3.475 \AA$ and $2.137 \AA$, which are somewhat extended from the regular interlayer spacing of the graphite viz. $d_{002}=3.356 \AA$ and $d_{101}=$ $2.034 \AA^{44}$ The larger $d_{002}$ and $d_{101}$ values of the ${ }^{\mathrm{PC}}-\mathrm{SO}_{3} \mathrm{H}$ compared to that of ideal graphite implied that the carbon is functionalized with different elements viz. oxygen and sulfur. Because of the functionalization the graphitic carbon in PC$\mathrm{SO}_{3} \mathrm{H}$ is more extended and exfoliated.

The thermal stability and the decomposition profile of the PC- $\mathrm{SO}_{3} \mathrm{H}$ were determined by the Thermogravimetric Analysis

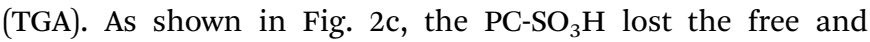
absorbed water in the molecular space from a temperature range from 50 to $250{ }^{\circ} \mathrm{C}$. The major decomposition of the adsorbent started from about $325{ }^{\circ} \mathrm{C}$ and a complete decomposition of the $\mathrm{PC}-\mathrm{SO}_{3} \mathrm{H}$ was observed at a temperature of about $525{ }^{\circ} \mathrm{C}$ and above. Thus, the TGA curve indicated that the PC$\mathrm{SO}_{3} \mathrm{H}$ has good thermal stability and is free from any metal oxide impurities. 

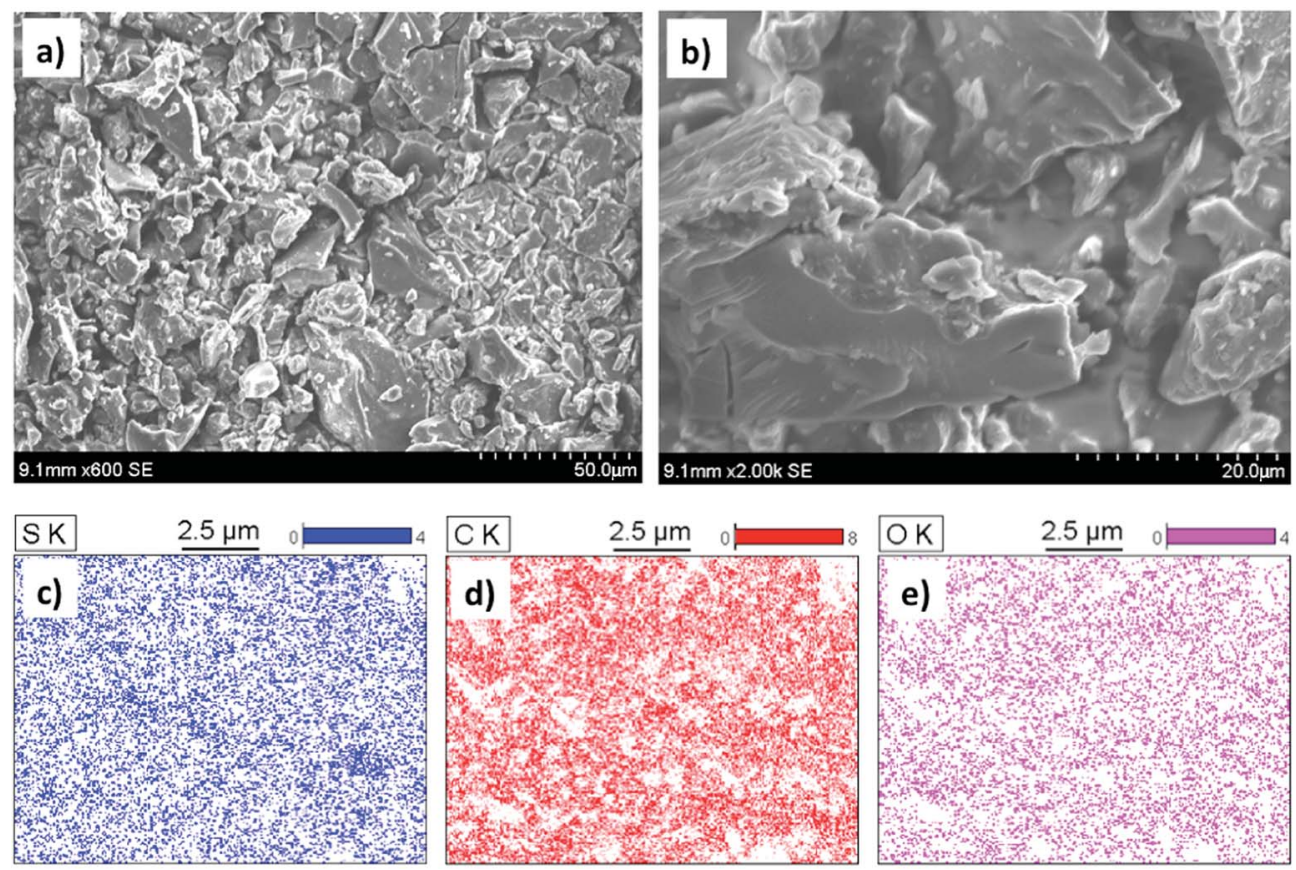

Fig. 1 ( $a$ and b) SEM images of the $\mathrm{PC}-\mathrm{SO}_{3} \mathrm{H}$ with varying magnifications and $(c-e)$ elemental mapping images of the $\mathrm{PC}-\mathrm{SO}{ }_{3} \mathrm{H}$ depicting the presence of sulfur, carbon and the oxygen.

Fourier transform infrared (FTIR) spectroscopic analysis was conducted on the pine cone before and after the sulfonation to identify the differences in the change in the functional groups

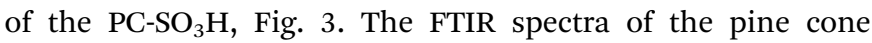

showed the presence of $\mathrm{OH}$, aliphatic $\mathrm{CH}$, carbonyl $(\mathrm{C}=\mathrm{O})$, and aromatic ring $\mathrm{C}=\mathrm{C}$ functional groups by their characteristic stretching vibrations at 3280, 2919, 1727, and $1604 \mathrm{~cm}^{-1}$, respectively. The substituted aromatic ring and $\mathrm{CH}$ rocking

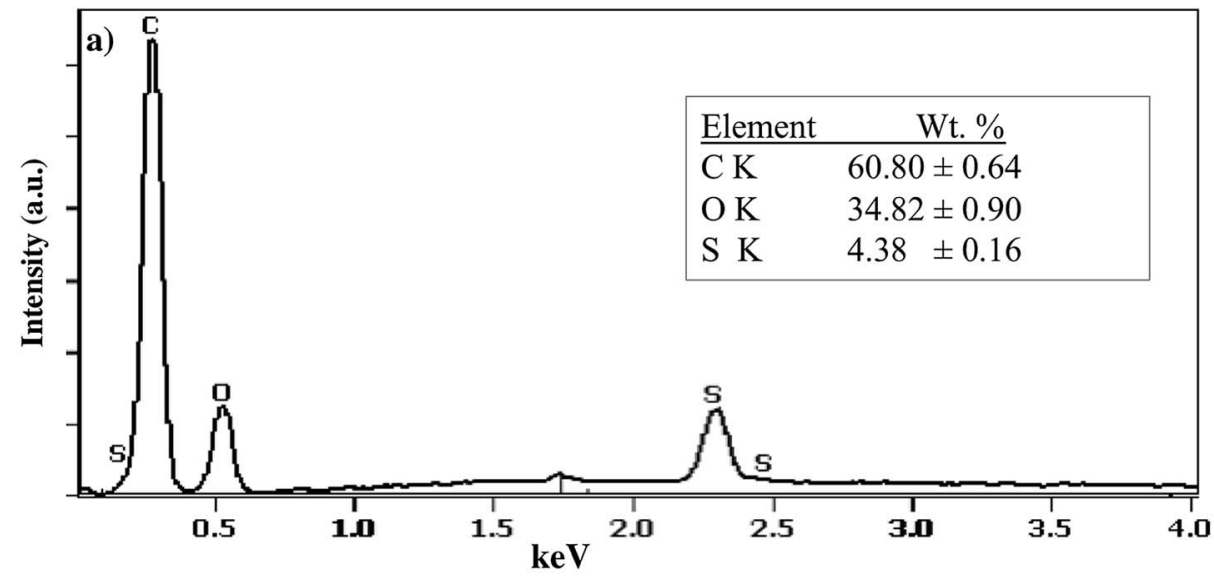

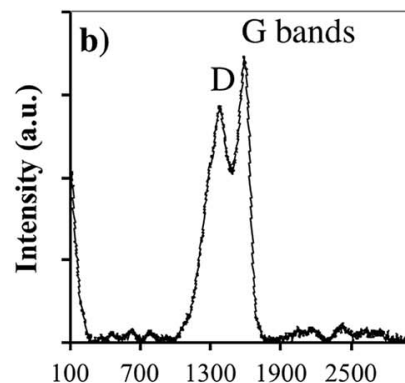

Raman shift ( $\left.\mathbf{c m}^{-1}\right)$
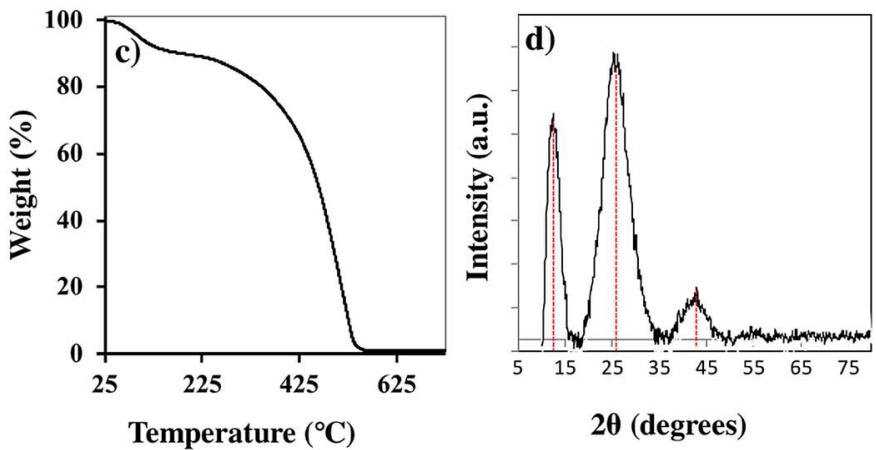

Fig. 2 (a) EDS spectra showing the elemental composition, (b) Raman spectra shows the carbonaceous nature (c) the thermal gravimetric curve depicts the thermal stability and (d) XRPD pattern shows the crystalline carbonaceous nature of the $\mathrm{PC}-\mathrm{SO}_{3} \mathrm{H}$. 


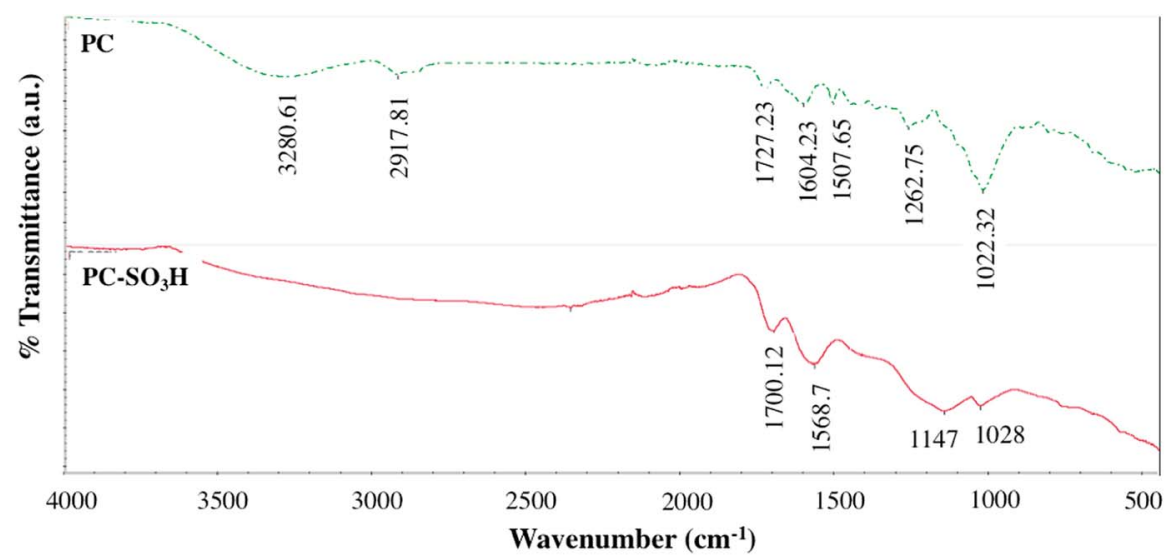

Fig. 3 FTIR spectrum of the pine cone before and after the $\mathrm{H}_{2} \mathrm{SO}_{4}$ treatment.

vibrations could be located at 1472 and $1380 \mathrm{~cm}^{-1}$, respectively. The asymmetric bending vibration of $\mathrm{CH}_{2}$, the $\mathrm{CO}$ stretching of ether of cellulose, and the phenolic $\mathrm{COH}$ stretching could be assigned at $1430 \mathrm{~cm}^{-1}, 1022 \mathrm{~cm}^{-1}$, and $1262 \mathrm{~cm}^{-1}$, respectively. In addition, two peaks at $1171 \mathrm{~cm}^{-1}$ and $1112 \mathrm{~cm}^{-1}$ could be assigned to the bending vibrations of $\mathrm{CO}$. All these vibrations suggested the presence of alcohol, aromatic ring, methylene bridge and ether functional groups in the pristine pine cone.

After the sulfuric acid treatment, new peak originated at $\sim 1147 \mathrm{~cm}^{-1}$, which could be attributed to the $-\mathrm{SO}_{3} \mathrm{H}$ group in the

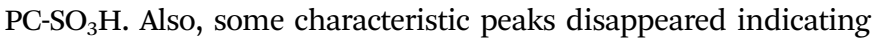
the change in functional groups after the sulfuric acid reflux. For example, the $\mathrm{OH}$ peak of the pristine pine cone became almost flat, which indicated that the $\mathrm{H}_{2} \mathrm{SO}_{4}$ reflux caused the dehydration of the pine cone. The dehydration also converted the pine cone into a carbonaceous material. Therefore, from the Raman and FTIR spectroscopic analyses it could be concluded that the $\mathrm{H}_{2} \mathrm{SO}_{4}$ reflux caused the carbonization as well as sulfonation to the pine cone.

The composition of the $\mathrm{PC}^{-} \mathrm{SO}_{3} \mathrm{H}$ was further analyzed by high resolution X-ray Photoelectron Spectroscopy (XPS). The

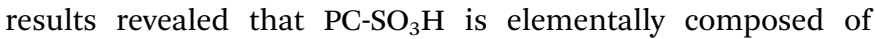
carbon, oxygen and sulfur in which the sulfur is mainly associated with $-\mathrm{SO}_{3} \mathrm{H}$ functional group. Fig. $4 \mathrm{~d}$ shows the $\mathrm{S} 2 \mathrm{p} 3 / 2$ and S 2p1/2 doublet with binding energies of about $169 \mathrm{eV}$, which could be assigned for the sulfonic acid functional group $\left(-\mathrm{SO}_{3} \mathrm{H}\right) \cdot{ }^{45-47}$ An additional peak was identified at about $165 \mathrm{eV}$, which could be assigned to the $\mathrm{S} 2 \mathrm{p} 1 / 2$ binding energy of the thiol group ${ }^{48}$ that may have retained from the parent pine cone.

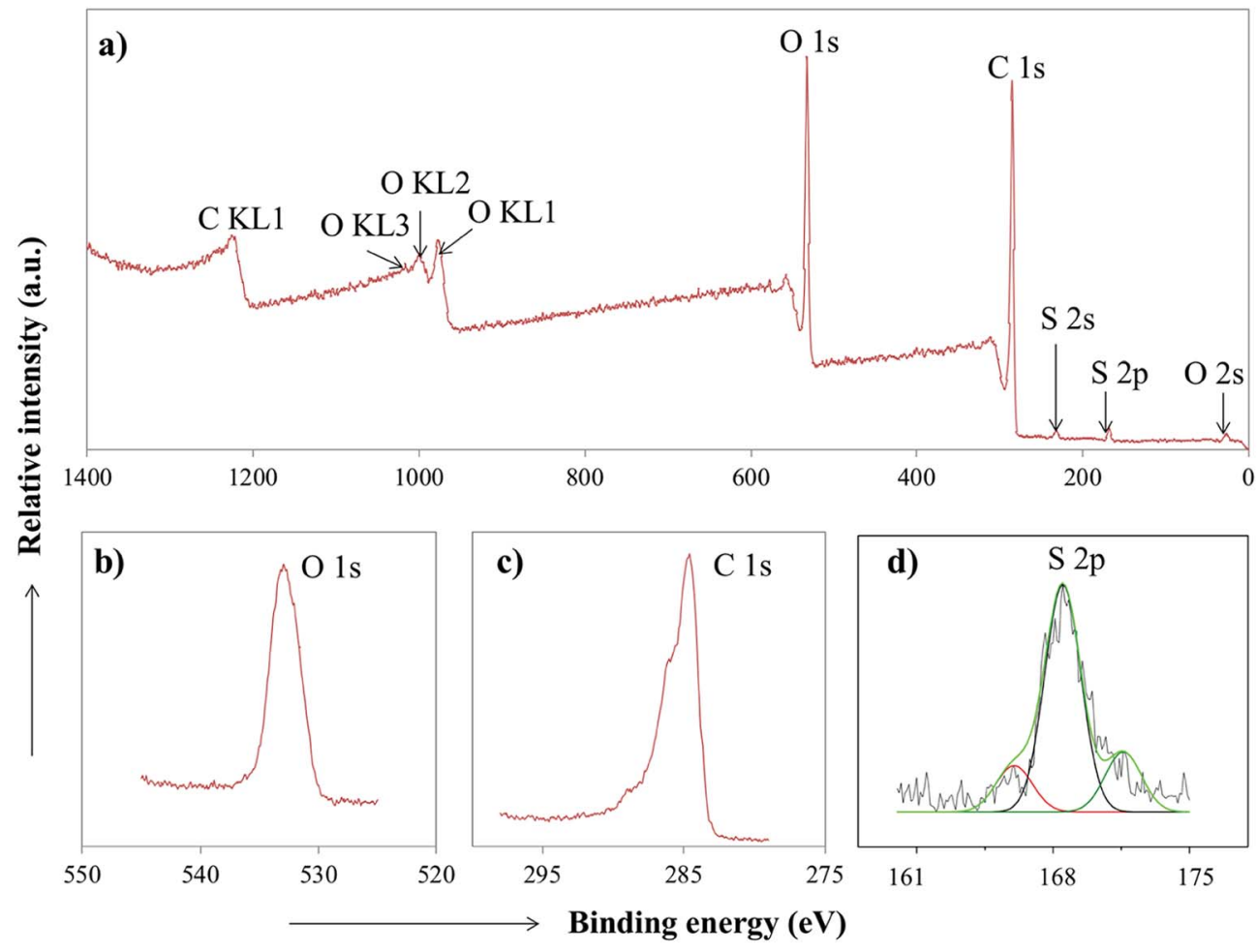

Fig. 4 (a) XPS spectra of $\mathrm{PC}-\mathrm{SO}_{3} \mathrm{H}$. High-resolution XPS spectrum of (b) $\mathrm{O}$ 1s (c) $\mathrm{C}$ 1s and (d) $\mathrm{S} 2 \mathrm{p}$ of the $\mathrm{PC}-\mathrm{SO}_{3} \mathrm{H}$. 


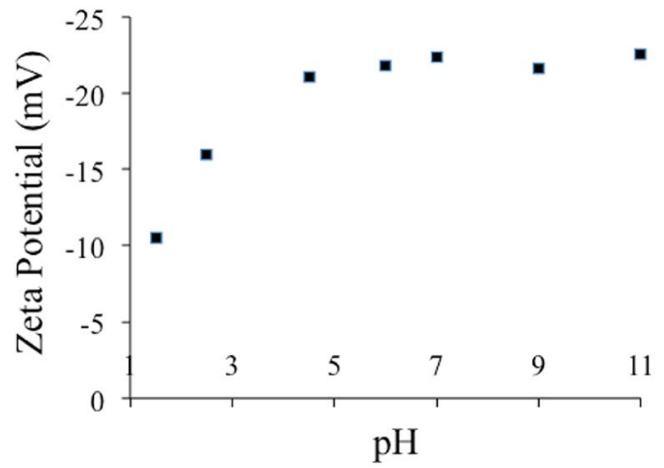

Fig. $5 \mathrm{pH}$-dependent zeta potential of the $\mathrm{PC}-\mathrm{SO}_{3} \mathrm{H}$ in water.

The zeta potential of the $\mathrm{PC}_{-} \mathrm{SO}_{3} \mathrm{H}$ was measured at the $\mathrm{pH}$ range of 1.5 to 11 in water, Fig. 5. It was found that the zeta potential of the $\mathrm{PC}_{-} \mathrm{SO}_{3} \mathrm{H}$ remains negative within the $\mathrm{pH}$ range. Due to the low $\mathrm{p} K_{\mathrm{a}}$ of the sulfonic acid $\left(\mathrm{R}-\mathrm{SO}_{3} \mathrm{H}, \mathrm{p} K_{\mathrm{a}} \sim-7\right)$, the $-\mathrm{SO}_{3} \mathrm{H}$ group deprotonates to form sulfonate $\left(\mathrm{PC}_{-} \mathrm{SO}_{3}{ }^{-}\right)$and thereby the adsorbent demonstrated negative zeta potential under the experimental $\mathrm{pH}$ range.

It was observed that at $\mathrm{pH} 1.5$ the negative zeta potential value is lowest and at $\mathrm{pH}$ above 4 the zeta potential remains almost similar. Therefore, at any $\mathrm{pH}$ within the range of 1.5 to

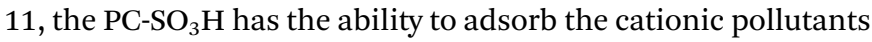
by electrostatic as well as hydrophobic interactions.

\subsection{Effect of $\mathbf{p H}$ on the adsorption of $\mathrm{MB}$ and $\mathrm{TC}$}

The solution $\mathrm{pH}$ plays an important role in the adsorption efficiency. Therefore, several experiments were performed where the $\mathrm{pH}$ on $\mathrm{MB}$ and $\mathrm{TC}$ was varied from 3 to 10 in order to investigate the $\mathrm{pH}$ dependence of the adsorption. As $\mathrm{MB}$ is a basic dye, it stays positively charged when dissolved in water. In basic $\mathrm{pH}, \mathrm{PC}_{-} \mathrm{SO}_{3} \mathrm{H}$ becomes more negatively charged, Fig. 5 . Therefore, at basic $\mathrm{pH}$ the negatively charged adsorbent and the positively charged dye have higher electrostatic attraction. As a result, the adsorption capacity of $\mathrm{PC}_{-} \mathrm{SO}_{3} \mathrm{H}$ for $\mathrm{MB}$ increased at higher pH, Fig. 6a. In addition, MB can adsorb on the adsorbent by $\pi-\pi$ interaction due to the conjugation in the MB structure the carbonaceous nature of the $\mathrm{PC}_{-} \mathrm{SO}_{3} \mathrm{H}$. Similar results were obtained by other studies, where the adsorption of cationic dyes was favored at basic $\mathrm{pH}^{49}$

On the other hand, the adsorption capacity for the TC onto PC- $\mathrm{SO}_{3} \mathrm{H}$ increased as the solution pH decreased, Fig. 6b. This response is assumed to cause by the protonation of the amine of the TC at acidic $\mathrm{pH}$ followed by the electrostatic interactions between the negatively charged sulfonate group of adsorbent and the ammonium group of the TC. Likewise MB, TC has conjugation in the structure and thereby it adsorbs on PC-SO3H by $\pi-\pi$ interaction as well. These results correlate with previously published reports. ${ }^{50}$

\subsection{Equilibrium adsorption capacity and the adsorption isotherms}

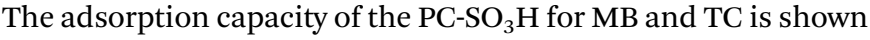
in Fig. 7. It was found that the equilibrium adsorption capacity $\left(Q_{\mathrm{e}}\right)$ for the MB adsorption increased with the increase in the solution $\mathrm{pH}$ and is vice versa for the adsorption of the TC. The adsorption capacity also increased with the increase in the initial concentration of $\mathrm{MB}$ and TC. The higher the initial concentration of adsorbate molecules, the stronger the driving forces to overcome the mass transfer resistances of adsorbate molecules from the aqueous to the solid phases, which results higher adsorption capacity. The data obtained from the equilibrium studies were analyzed according to Langmuir and Freundlich adsorption isotherm models. The $Q_{\mathrm{e}}$ was calculated by using the eqn (5). The adsorption capacities of $\mathrm{PC}^{-\mathrm{SO}_{3} \mathrm{H}}$ towards MB and TC with respect to the initial concentration and $\mathrm{pH}$ are shown in Fig. 7a and b. The $Q_{\mathrm{e}}$ was calculated to be about 1595 and $810 \mathrm{mg} \mathrm{g}^{-1}$ at initial MB concentration of 2000 and $1200 \mathrm{ppm}$ and at pH 10 and 7, respectively (Fig. 7a). The MB

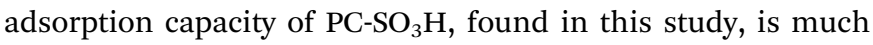
higher than the previously reported values, where pine cone derived adsorbent was prepared by other methods. ${ }^{38,51}$ For the adsorption of TC, the $Q_{\mathrm{e}}$ was measured to be 348 and $308 \mathrm{mg}$ $\mathrm{g}^{-1}$ at the initial concentrations of $500 \mathrm{ppm}$, and the $\mathrm{pH}$ of 3.5 and 6.5, respectively (Fig. 7a). However, the pristine and

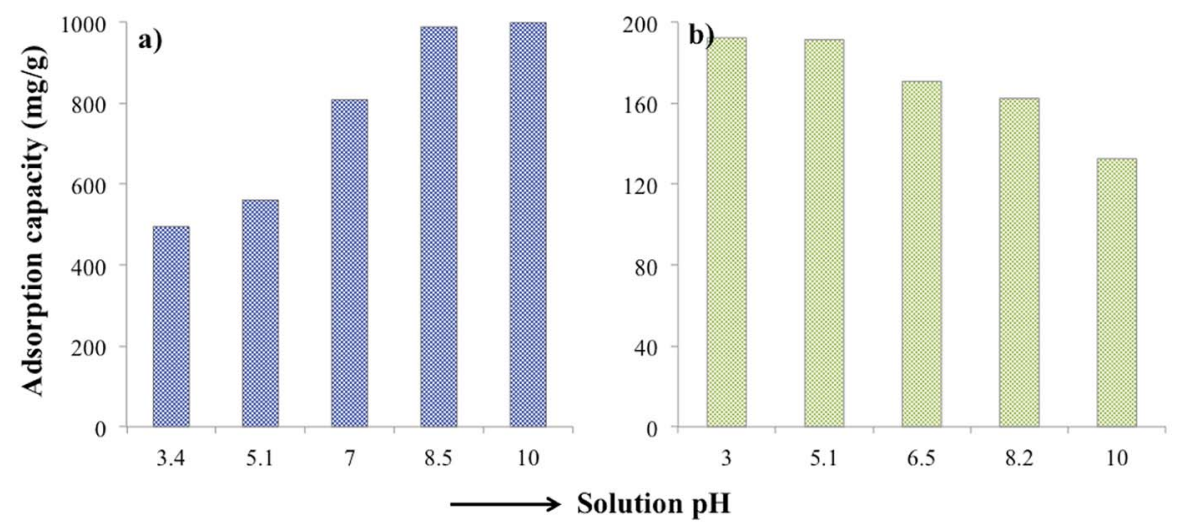

Fig. $6 \mathrm{pH}$ dependent adsorption of (a) $\mathrm{MB}$ and (b) $\mathrm{TC}$ by $\mathrm{PC}-\mathrm{SO}_{3} \mathrm{H}$, respectively. Initial $\mathrm{MB}$ concentration $=1000 \mathrm{mg} \mathrm{L}{ }^{-1}, \mathrm{~V}=20 \mathrm{~mL}$ and adsorbent $=20 \mathrm{mg}$; initial TC concentration $=200 \mathrm{mg} \mathrm{L}^{-1}, \mathrm{~V}=20 \mathrm{~mL}$ and adsorbent $=20 \mathrm{mg}$. 

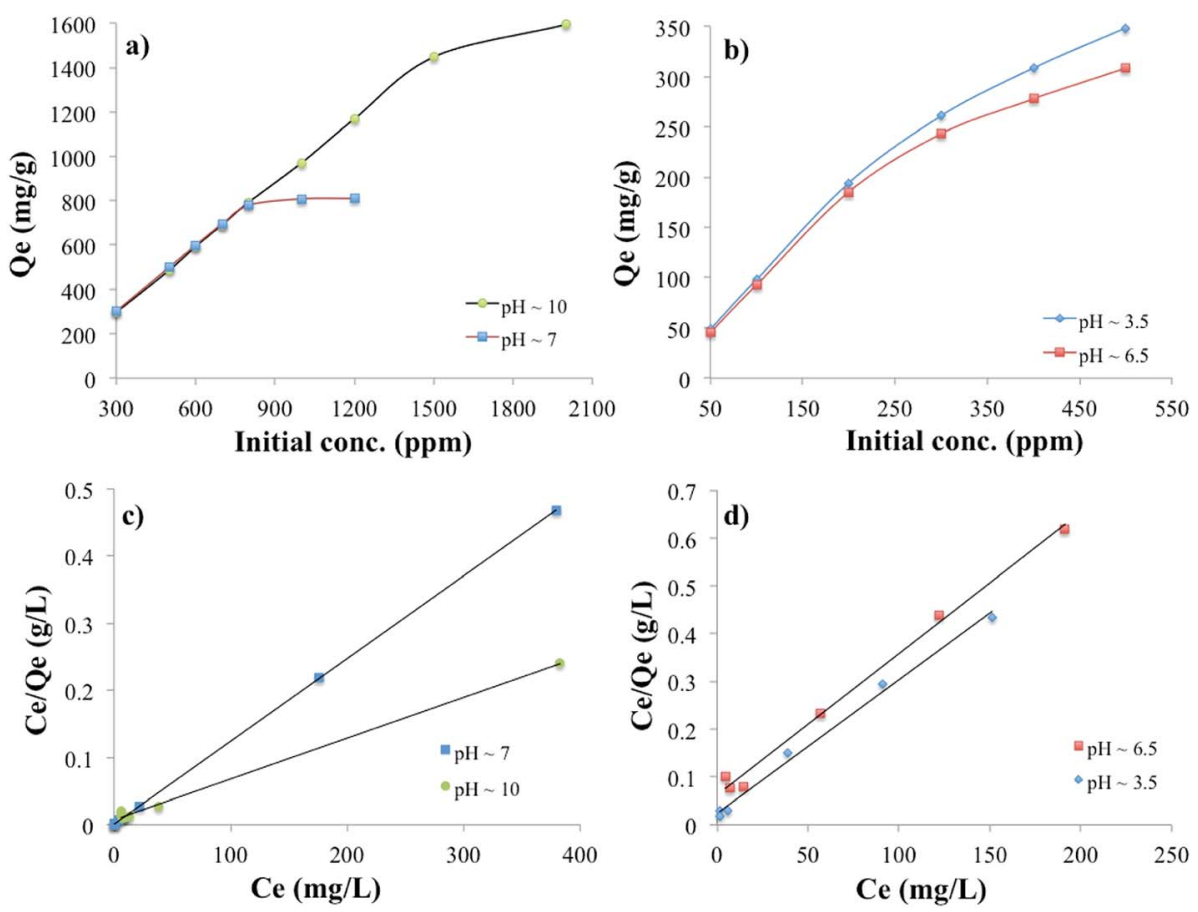

Fig. 7 Adsorption capacity of $\mathrm{PC}-\mathrm{SO}_{3} \mathrm{H}$ towards (a) $\mathrm{MB}$ and (b) TC at different initial pollutant concentrations and $\mathrm{pH}$. Corresponding Langmuir isotherm models for the adsorption of (c) $\mathrm{MB}$ and (d) $\mathrm{TC}$ onto $\mathrm{PC}-\mathrm{SO}_{3} \mathrm{H}$.

unmodified pine cone showed adsorption capacity of 67 and $28 \mathrm{mg} \mathrm{g}^{-1}$ at $\mathrm{pH} \sim 7$ for MB and TC, Fig. S3. $\dagger$ In comparison to the pristine pine cone, the sulfuric acid treated pine cone demonstrated an extraordinary increase in the adsorption capacity for MB and TC. In order to avoid the confusion that the $\mathrm{MB}$ and TC may undergo natural degradation, control experiments were performed without the $\mathrm{PC}_{-} \mathrm{SO}_{3} \mathrm{H}$. It was found that $\mathrm{MB}$ and TC did not degrade after $24 \mathrm{~h}$ of equilibration at room temperature $\left(23^{\circ} \mathrm{C}\right)$. Therefore, it could be inferred that the removal of these two pollutants from water happened by adsorption processes and sulfuric acid treatment did the extraordinary improvement in the adsorption capacity of the pine cone.

The linear form of the Langmuir isotherm model (eqn (1)), applied to the experimental data, is shown in Fig. 7c and d. A good fit of the experimental data with the Langmuir model isotherm suggested that the adsorption of $\mathrm{MB}$ and $\mathrm{TC}$ happened by monolayer type adsorption. Applying the Langmuir isotherm equation, the maximum adsorption capacity $\left(Q_{\mathrm{m}}\right)$ was calculated to be 1666.66 and $833.33 \mathrm{mg} \mathrm{g}^{-1}$ for MB at pH 10 and 7, respectively. The $Q_{\mathrm{m}}$ for TC was calculated to be 357.14 and $333.33 \mathrm{mg} \mathrm{g}^{-1}$ at $\mathrm{pH} 3.5$ and 6.5 , respectively. The Freundlich adsorption isotherm model was also applied to the batch adsorption data for the MB and TC, Fig. S4. $\dagger$ The linear correlation coefficient $\left(R^{2}\right)$ of 0.896 and 0.740 were obtained for the MB adsorption at $\mathrm{pH} 10$ and 7, respectively. The adsorption intensity $(n)$, calculated from the isotherm plots, are 10.78 and 5.53 at $\mathrm{pH} 7$ and 10, respectively. Since, the value of $n$ is larger

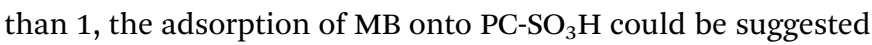
as a favorable process at both $\mathrm{pH}^{.52}$ The $R^{2}$ values of the Freundlich isotherms for the adsorption of TC were found to be
0.843 and 0.838 at $\mathrm{pH} 3.5$ and 6.5, respectively. The values of $n$ were calculated to be 2.87 and 2.25 at pH 3.5 and 6.5, respectively. Therefore, the adsorption of TC onto the $\mathrm{PC}^{-\mathrm{SO}_{3} \mathrm{H} \text { could }}$ be suggested as a favorable process at both $\mathrm{pH}$.

\subsection{Adsorption kinetics}

The time-dependent adsorption of $\mathrm{MB}$ and TC by the $\mathrm{PC}^{-\mathrm{SO}_{3} \mathrm{H}}$ is shown in Fig. 8a. The results demonstrated a fast adsorption

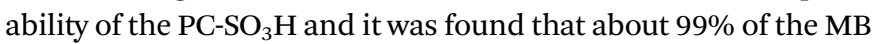
and TC was adsorbed within 100 minutes at $\mathrm{pH} 7$ and 3.5 ,

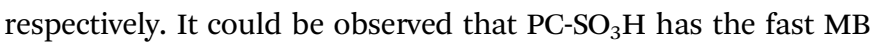
and TC removal ability from the high concentration of $\mathrm{MB}$ and TC solutions viz. 200 and $50 \mathrm{ppm}$ for MB and TC, respectively. The adsorption kinetics of $\mathrm{MB}$ and $\mathrm{TC}$ on $\mathrm{PC}^{-\mathrm{SO}_{3} \mathrm{H}}$ were investigated by two most commonly used kinetic models viz. pseudosecond-order and pseudo-first-order models. Fig. 8b shows the linear form of the Pseudo-second-order kinetic model, which was obtained by using eqn (3). For the adsorption of MB and TC, the relationship between the $t / Q_{t}$ versus time was found to be linear having the correlation coefficients $\left(R^{2}\right)$ values of 1 . This suggested that the adsorption followed the pseudo-second-order kinetic model. The values of pseudo-second-order rate constants of MB adsorption were calculated to be 0.171 and 0.379 [g $\left.\left(\mathrm{mg}^{-1} \mathrm{~min}^{-1}\right)\right]$ for $\mathrm{MB}$ and $\mathrm{TC}$, respectively.

However, the linear form of the pseudo-second-order kinetic model, applied on the experimental data by plotting $\log \left(Q_{\mathrm{e}}-Q_{t}\right)$ versus time (eqn (4)), gave a non-linear trend, Fig. S5. $\dagger$ The poor $R^{2}$ values suggested that the pseudo-first-order kinetic model is inapplicable for the adsorption of $\mathrm{MB}$ and TC onto the $\mathrm{PC}^{-\mathrm{SO}_{3} \mathrm{H}}$. 


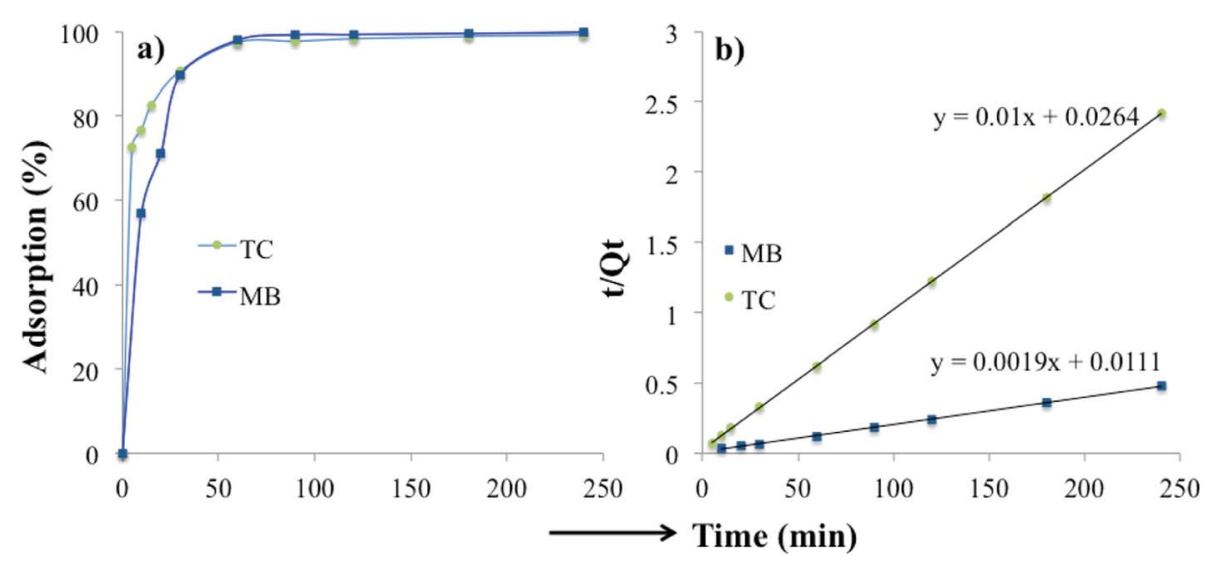

Fig. 8 (a) Time-dependent percent adsorption of MB and TC and (b) the corresponding pseudo-second-order kinetics adsorption. Initial MB concentration $=200 \mathrm{mg} \mathrm{L}^{-1}, \mathrm{~V}=40 \mathrm{~mL}$ and adsorbent $=20 \mathrm{mg}$; initial TC concentration $=50 \mathrm{ppm}, \mathrm{V}=20 \mathrm{~mL}$ and adsorbent $=10 \mathrm{mg}$.

\subsection{Adsorption thermodynamics}

Various thermodynamic parameters such as enthalpy, adsorption free energy and entropy changes were calculated for the adsorption of $\mathrm{MB}$ and $\mathrm{TC}$ over $\mathrm{PC}-\mathrm{SO}_{3} \mathrm{H}$. Fig. 9 depicts the temperature-dependent adsorption capacities at temperatures of 23,40 and $60{ }^{\circ} \mathrm{C}$. It was observed that the adsorption capacity for $\mathrm{MB}$ and $\mathrm{TC}$ increased with the experimental temperature, which indicated an endothermic adsorption process. At constant $\mathrm{pH}$, the adsorption capacity for MB increased from 440 to $534 \mathrm{mg} \mathrm{g}^{-1}$ when the temperature was increased from 23 to $60{ }^{\circ} \mathrm{C}$, Fig. 9a. For TC, the adsorption capacity increased from 309 to $388 \mathrm{mg} \mathrm{g}^{-1}$ with the same temperature increase, Fig. $9 \mathrm{~b}$. At elevated temperatures, the viscosity of the solution decreases and thereby the rate of diffusion of the adsorbate molecules across the external boundary layer and in the internal pores of the adsorbent particle increases. ${ }^{53}$ As a result, the adsorption capacity at elevated temperature increases. At elevated temperature, the adsorbent can be more hydrated, and the surface can become exposed to the adsorbate molecules to increase the adsorption capacity.

The Gibbs free energy change $(\Delta G)$ of adsorption was calculated using the following equation. ${ }^{54}$

$$
\Delta G=-R T \ln \left(K_{\mathrm{C}}\right)
$$

where $R$ is the universal gas constant $\left(8.31 \mathrm{~J} \mathrm{~mol}^{-1} \mathrm{~K}^{-1}\right)$ and $K_{\mathrm{C}}$ is the thermodynamic equilibrium constant $\left(\mathrm{L} \mathrm{g}^{-1}\right)$, which can be obtained from the ratio of $Q_{\mathrm{e}}$ to $C_{\mathrm{e}}$.

The thermodynamic parameters for the adsorption $\mathrm{MB}$ and TC over $\mathrm{PS}_{-} \mathrm{SO}_{3} \mathrm{H}$ are shown in Table 1.

The Gibbs free energy change $(\Delta G)$ for the adsorption of $\mathrm{MB}$ at temperature 23,40 , and $60{ }^{\circ} \mathrm{C}$ was calculated to be -76.83 , -96.90 , and $-116.26 \mathrm{~kJ} \mathrm{~mol}^{-1}$, respectively. The $\Delta G$ for the adsorption of TC at temperature 23,40 , and $60{ }^{\circ} \mathrm{C}$ was calculated to be $-103.11,-142.50$, and $-190.45 \mathrm{~kJ} \mathrm{~mol}^{-1}$, respectively. The negative values of the $\Delta G$ suggested that the

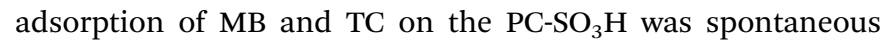
process. The magnitude of the $\Delta G$ increased with increasing temperature indicating that the adsorption of $\mathrm{MB}$ and TC molecules is favorable at higher temperatures.

Additionally, the enthalpy and entropy changes $(\Delta H$ and $\Delta S$ ) of adsorption were obtained using the van't Hoff equation..$^{55}$

$$
\ln K_{\mathrm{C}}=-\frac{\Delta H}{R T}+\frac{\Delta S}{R}
$$

The van't Hoff graphs were obtained by plotting $\ln \left(K_{\mathrm{C}}\right)$ vs. $1 /$ $T .^{56,57}$ To determine $K_{\mathrm{C}}$, the ratio of $Q_{\mathrm{e}}$ to $C_{\mathrm{e}}$ was obtained from the adsorption experiments, where the initial MB concentration was $600 \mathrm{ppm}$. For TC, the initial concentration of $400 \mathrm{ppm}$ was

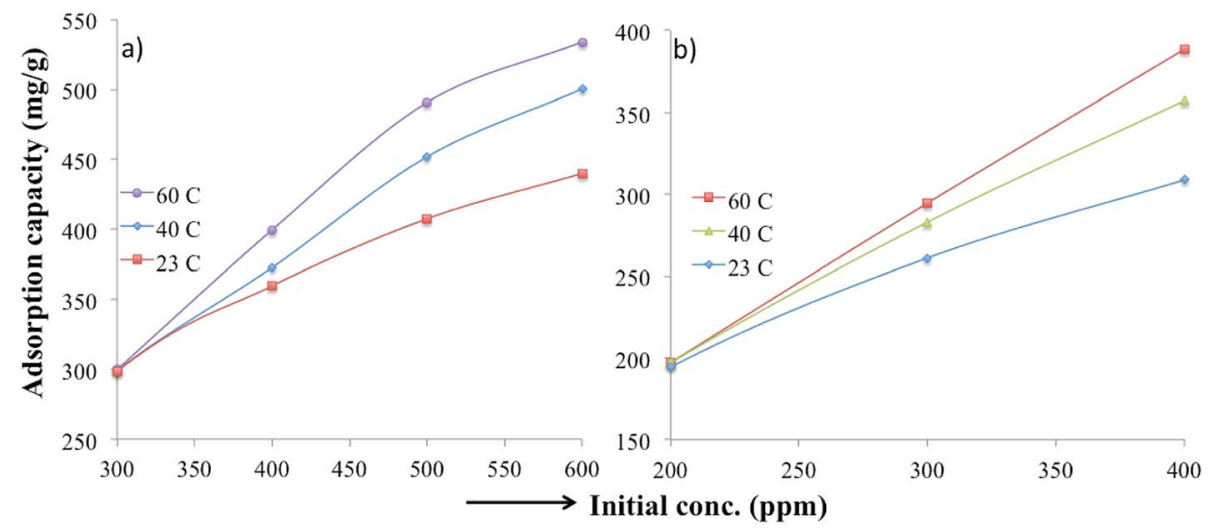

Fig. 9 Temperature-dependent adsorption capacities of the $\mathrm{PC}-\mathrm{SO}_{3} \mathrm{H}$ for (a) $\mathrm{MB}$ and (b) $\mathrm{TC}$ at $\mathrm{pH} 3.25$ and 3.75 , respectively. 
Table 1 Thermodynamic parameters for the adsorption MB and TC over PS- $\mathrm{SO}_{3} \mathrm{H}$

\begin{tabular}{|c|c|c|c|c|c|c|}
\hline Adsorbent & Adsorbates & Temperature (K) & $K_{\mathrm{C}}\left(\mathrm{L} \mathrm{g}^{-1}\right)$ & $\Delta G\left(\mathrm{~kJ} \mathrm{~mol}^{-1}\right)$ & $\Delta H\left(\mathrm{~kJ} \mathrm{~mol}^{-1}\right)$ & $\Delta S\left(\mathrm{~J} \mathrm{~mol}^{-1} \mathrm{~K}^{-1}\right)$ \\
\hline \multirow[t]{5}{*}{$\mathrm{PC}-\mathrm{SO}_{3} \mathrm{H}$} & \multirow[t]{2}{*}{ MB } & 296 & 22.74 & -76.83 & \multirow[t]{2}{*}{23.82} & \multirow[t]{2}{*}{106.67} \\
\hline & & 313 & 41.49 & -96.90 & & \\
\hline & \multirow[t]{3}{*}{$\mathrm{TC}$} & 296 & 66.16 & -103.11 & \multirow[t]{3}{*}{59.57} & \multirow[t]{3}{*}{236.02} \\
\hline & & 313 & 239.51 & -142.50 & & \\
\hline & & 333 & 975.20 & -190.45 & & \\
\hline
\end{tabular}

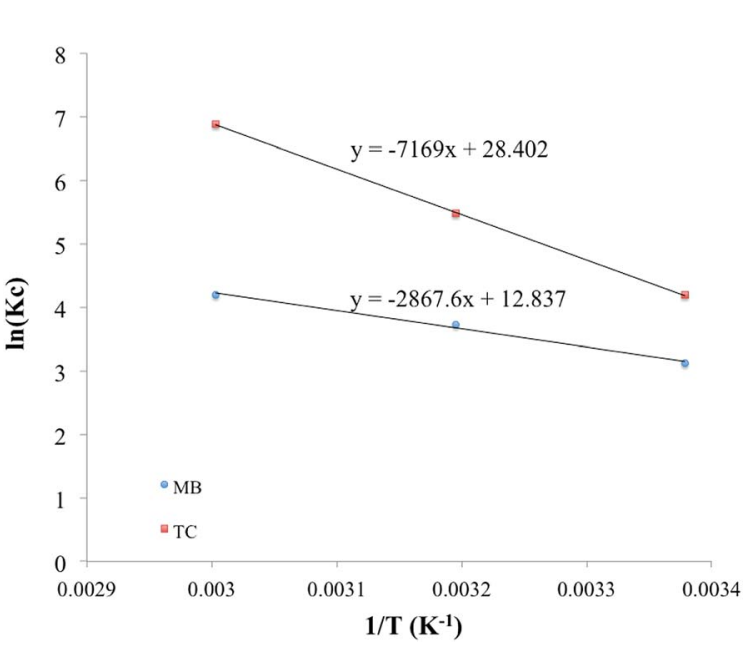

Fig. 10 van't Hoff plots to obtain the $\Delta H$ and $\Delta S$ of the MB and TC adsorptions.

used to determine $K_{\mathrm{C}}$. The $\Delta H$ values, calculated from the van't Hoff plot (Fig. 10), were +23.82 and $+59.87 \mathrm{~kJ} \mathrm{~mol}^{-1}$ for $\mathrm{MB}$ and $\mathrm{TC}$, respectively. The positive values further indicate the endo-

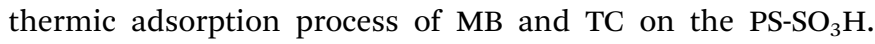
Moreover, as the $\Delta H$ values are less than $80 \mathrm{~kJ} \mathrm{~mol}^{-1}$, the adsorption process could be considered to happen by physisorption.

In addition, the values of the entropy changes $(\Delta S)$ were determined from the van't Hoff plot, Fig. 10. The $\Delta S$ values were calculated as $+106.67,+236.02 \mathrm{~J} \mathrm{~mol}^{-1} \mathrm{~K}^{-1}$ for $\mathrm{MB}$ and TC, respectively. The positive values of the entropy changes indicated that the increase in the degrees of freedom or randomness at the adsorbent-adsorbate interface during the adsorption process. As $\Delta S$ is positive, applying the equation $(\Delta G$ $=\Delta H-T \Delta S$ ) it could be concluded that the spontaneity of the $\mathrm{MB}$ and TC adsorption is entropically favored.

As far our experimental parameters, the optimum conditions for the adsorption of $\mathrm{MB}$ was found at $\mathrm{pH} \sim 10$, temperature $60{ }^{\circ} \mathrm{C}$, and after $24 \mathrm{~h}$ of equilibration time. However, for the adsorption of $\mathrm{TC}$, the optimum condition was found at $\mathrm{pH}$ $\sim 3.5$, temperature $60^{\circ} \mathrm{C}$, and after $24 \mathrm{~h}$ of equilibration time.

\subsection{Adsorption of $\mathrm{MB}$ and TC from tap water}

In addition to the organic pollutants (MB, TC), the wastewater usually contains many other soluble organic and inorganic species, which impede the adsorption efficiency. Therefore, the efficacy of the $\mathrm{PC}-\mathrm{SO}_{3} \mathrm{H}$ was studied for the removal $\mathrm{MB}$ and TC of tap water as a realistic water matrix. The equilibrium adsorption capacity towards MB was found to be 880.6 at an initial $\mathrm{MB}$ concentration of $800 \mathrm{ppm}$ and $\mathrm{pH} \mathrm{7,} \mathrm{Fig.} \mathrm{11.} \mathrm{The}$ equilibrium adsorption capacity towards TC was measured to be $306.8 \mathrm{mg} \mathrm{g}^{-1}$ at an initial TC concentration of $500 \mathrm{ppm}$ and at $\mathrm{pH}$ about 7 . From this study, it was found that the soluble ions present in the tap water had a minimal effect on the adsorption capacity. Therefore, it could be suggested that the PC-SO $\mathrm{S}_{3} \mathrm{H}$ could potentially be utilized for the removal of $\mathrm{MB}$ and TC from drinking or tap water matrices.

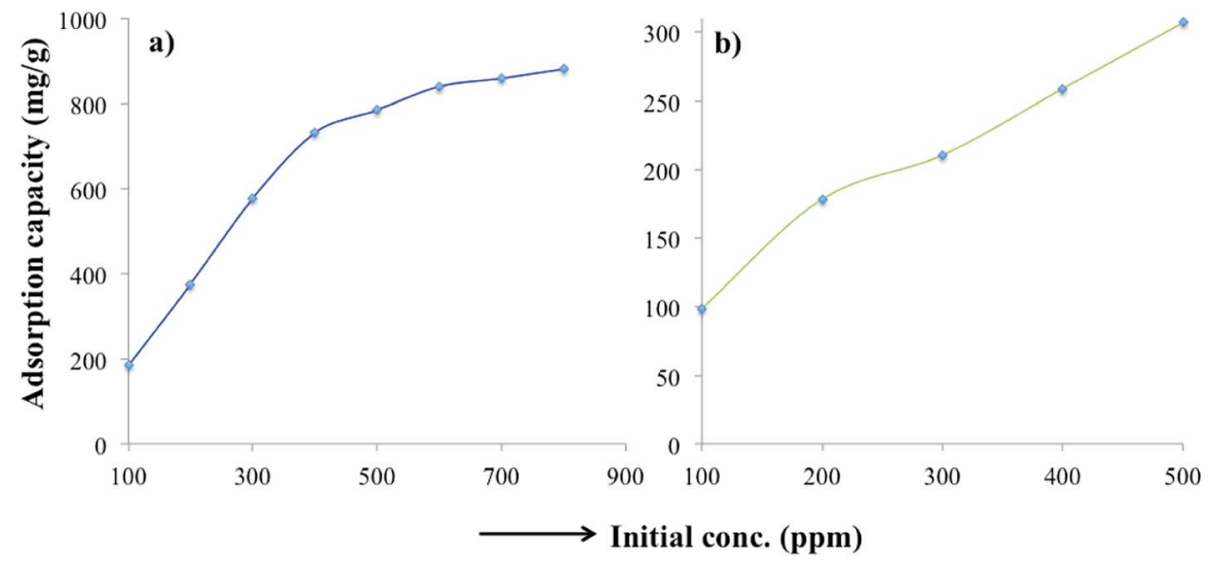

Fig. 11 Adsorption capacity of $\mathrm{PC}-\mathrm{SO}_{3} \mathrm{H}$ for (a) $\mathrm{MB}$ and (b) TC from tap water matrix. Initial $\mathrm{MB}$ concentration $=100-800 \mathrm{mg} \mathrm{L}{ }^{-1}, \mathrm{~V}=20 \mathrm{~mL}$ and adsorbent $=10 \mathrm{mg}$; initial TC concentration $=100-500 \mathrm{mg} \mathrm{L}^{-1}, \mathrm{~V}=20 \mathrm{~mL}$ and adsorbent $=20 \mathrm{mg}$. 


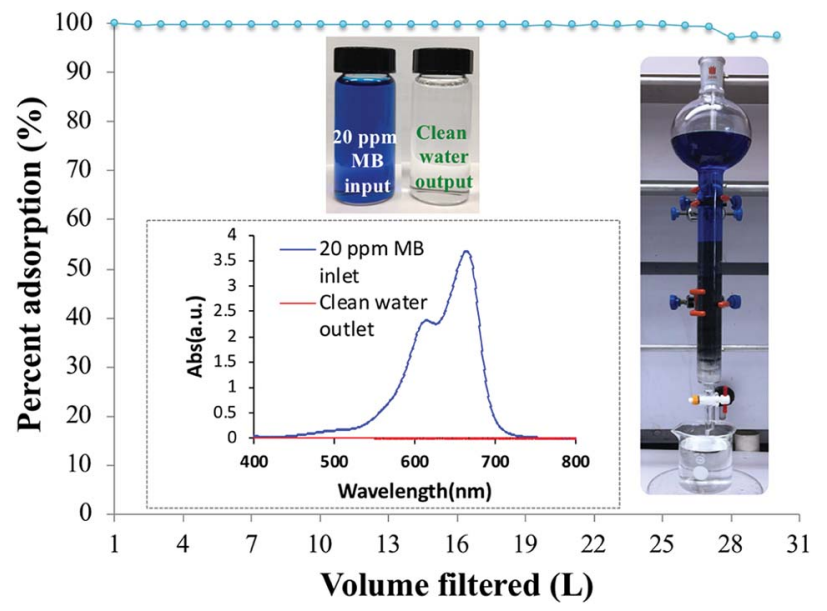

Fig. 12 MB removal (\%) vs. the volume of the $20 \mathrm{ppm}$ MB solution filtered through the column. Insets: the feed MB solution and the clean filtrate; UV-vis spectrum of the 20 ppm MB solution and the clean filtrate; an operating filter.

\subsection{Adsorbent packed column for continuous adsorption of MB}

To evaluate the dynamic behavior of $\mathrm{MB}$ removal by $\mathrm{PC}-\mathrm{SO}_{3} \mathrm{H}$, a continuous flow adsorption experiment was conducted by using a laboratory-scale packed glass column with the dimensions reported in the experimental section. The adsorption capacity of the $\mathrm{PC}_{-} \mathrm{SO}_{3} \mathrm{H}$ towards $\mathrm{MB}$ from tap water was examined under the continuous flow conditions through the packed column, Fig. 12.

The column filtered up to 27 liters of 20 ppm MB solution from tap water with $100 \%$ removal efficiency. After that, the column started to lose its efficiency and on the $30^{\text {th }}$ liter the removal efficiency dropped to $\sim 98 \%$. The inset picture shows a functional packed column and the vials shows the $20 \mathrm{ppm} \mathrm{MB}$ solution inlet and the clean water outlet. As a control, a similar packed column was filled with sand and cotton support, without the $\mathrm{PC}-\mathrm{SO}_{3} \mathrm{H}$, and $20 \mathrm{ppm} \mathrm{MB}$ solution was filtered through it. It was found that the sand packed column could filter only about $0.5 \mathrm{~L}$ of water with $100 \%$ removal efficiency.
Afterwards, the column drastically lost its efficiency and removed $90 \% \mathrm{MB}$ at $0.75 \mathrm{~L}$ of water filtered. Therefore, from the continuous adsorption study through the column, it could be suggested that the $\mathrm{PC}-\mathrm{SO}_{3} \mathrm{H}$ could be potentially utilized for the efficient removal of $\mathrm{MB}$ from the drinking or tap water matrices.

\subsection{Comparison of the adsorption capacities with other adsorbents}

Previous studies have investigated the adsorptive removal of $\mathrm{MB}$ and TC from aqueous solution utilizing low-cost based materials. The results of Table 2 illustrate the comparison of the adsorption capacities of different adsorbents under similar experimental conditions.

It shows that the $\mathrm{PC}-\mathrm{SO}_{3} \mathrm{H}$ has better adsorption capacities for $\mathrm{MB}$ and $\mathrm{TC}$ compared to many other adsorbents such as raw or modified pine cone, activated charcoal, graphene, carbon nanotubes, sulfonated scrap tire and sulfonated spent tea leaf. Therefore, we believe that the $\mathrm{PC}-\mathrm{SO}_{3} \mathrm{H}$ could be a potential candidate as the high-capacity and low-cost adsorbent for the removal of $\mathrm{MB}$ and $\mathrm{TC}$ in areas with insufficient resources.

\subsection{Suggested adsorption mechanism}

Adsorption can happen by a number of different interactions $v i z$. ionic or electrostatic interaction, $\pi-\pi$ interaction, hydrogen bonding, van der Waals interaction, hydrophobic interaction, and so on. The chemical structure of MB and TC consists of aromatic ring with different degree of conjugations, which favors their adsorption on the carbonaceous adsorbent by the $\pi-\pi$ stacking interaction, Scheme 3 . Additionally, MB is a cationic dye and thereby it exists as positively charged in aqueous solution. From the zeta potential measurements, it was found that the $\mathrm{PC}-\mathrm{SO}_{3} \mathrm{H}$ exists as negatively charged $\left(\mathrm{PC}-\mathrm{SO}_{3}{ }^{-}\right)$ throughout the $\mathrm{pH}$ range of 1.5 to 11 , Fig. 5. Therefore, MB gets adsorbed on the $\mathrm{PC}-\mathrm{SO}_{3} \mathrm{H}$ surface by the electrostatic attractive forces between the negative charge of the sulfonate group of the $\mathrm{PC}-\mathrm{SO}_{3} \mathrm{H}$ and the positive charge of the MB.

On the other hand, TC has an aromatic ring with an extended conjugation system with various functional groups viz. phenol,

Table 2 Comparison of adsorption capacities of various adsorbents for the removal of MB and TC from deionized water

\begin{tabular}{|c|c|c|c|c|c|}
\hline Adsorbent & Pollutants & $Q_{\max }\left(\mathrm{mg} \mathrm{g}^{-1}\right)$ & $T(\mathrm{~K})$ & $\mathrm{pH}$ & References \\
\hline Raw pine cone & MB & 129 & 298 & 9 & 38 \\
\hline Base modified pine cone & MB & 142 & 298 & 9 & 38 \\
\hline Graphene & MB & 153 & 293 & 7 & 59 \\
\hline Sulfonated tea waste & MB & 1007 & 298 & 10 & 60 \\
\hline Bamboo charcoal & $\mathrm{TC}$ & 23.5 & 303 & 7 & 61 \\
\hline Sulfonated tea waste & $\mathrm{TC}$ & 381 & 298 & 4 & 60 \\
\hline Sulfonated saw dust & TC & 270 & 298 & 4 & 63 \\
\hline $\mathrm{PC}^{-\mathrm{SO}_{3} \mathrm{H}}$ & MB & 1667 & 298 & 10 & This work \\
\hline $\mathrm{PC}-\mathrm{SO}_{3} \mathrm{H}$ & MB & 833 & 298 & 7 & This work \\
\hline $\mathrm{PC}-\mathrm{SO}_{3} \mathrm{H}$ & $\mathrm{TC}$ & 357 & 298 & 3.5 & This work \\
\hline $\mathrm{PC}-\mathrm{SO}_{3} \mathrm{H}$ & $\mathrm{TC}$ & 333 & 298 & 6.5 & This work \\
\hline
\end{tabular}




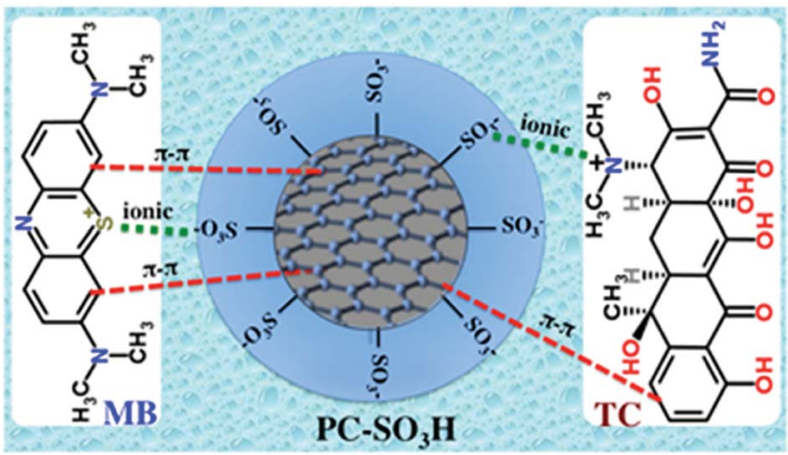

Scheme 3 Proposed adsorption mechanism of the $\mathrm{PC}-\mathrm{SO}_{3} \mathrm{H}$ towards the $M B$ and $T C$.

alcohol, ketone, and tertiary amine and amide. At acidic $\mathrm{pH}<$ 3.3, TC becomes positively charged by the tertiary ammonium functional groups, whereas the $\mathrm{PC}^{-} \mathrm{SO}_{3} \mathrm{H}$ stays as $\mathrm{PC}^{-} \mathrm{SO}_{3}{ }^{-}$, Fig. 5. Therefore, at acidic $\mathrm{pH}$ the $\mathrm{TC}$ adsorption is favored by the ionic interaction between the sulfonate group of the adsorbent and the tertiary ammonium group of the TC. In the $\mathrm{pH}$ range from 3.3 to 7.68 , the TC becomes mostly zwitterionic. Thus, the electrostatic interaction remains almost same within this range of $\mathrm{pH}$ and thereupon the adsorption capacity remains nearly identical. At basic $\mathrm{pH}>8$, the TC molecule becomes negatively charged by the phenolate and the hydrox-

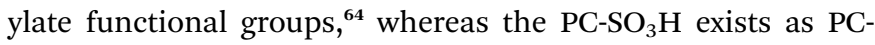
$\mathrm{SO}_{3}{ }^{-}$, Fig. 5. Therefore, the electrostatic repulsive forces between the sulfonate group of the adsorbent and the negatively charged TC molecule lowers the adsorption capacity.

\section{Conclusion}

In conclusion, the preparation of a high-capacity and low-cost adsorbent based on pine cone is reported by a simple method of sulfuric acid treatment. As far our experimental conditions, the maximum adsorption of $\mathrm{MB}$ was found at $\mathrm{pH} \sim 10$, temperature $60{ }^{\circ} \mathrm{C}$, and after $24 \mathrm{~h}$ of equilibration time. However, for the adsorption of TC, the maximum adsorption was found at $\mathrm{pH} \sim 3.5$, temperature $60{ }^{\circ} \mathrm{C}$, and after $24 \mathrm{~h}$ of equilibration time. The maximum adsorption capacities were found to be $1666.66 \mathrm{mg} \mathrm{g}^{-1}$ for MB and $357.14 \mathrm{mg} \mathrm{g}^{-1}$ for TC. The pseudo-second-order kinetic model was in best fit with the experimental results. The adsorption of MB and TC followed the Langmuir isotherm model with better fit than the Freundlich model. A lab made packed column was prepared using the adsorbent, which filtered up to $27 \mathrm{~L}$ of $20 \mathrm{ppm}$ MB solution from tap water with $100 \%$ removal efficiency. The sulfuric acid reflux method could be utilized for the preparation of high-capacity adsorbent from a wide variety of biomasses. The utilization of biomass to generate a high capacity and low-cost adsorbent can provide an environmentally friendly and sustainable way to remove anthropogenic pollutants from wastewater.

\section{Conflicts of interest}

There are no conflicts exist.

\section{Acknowledgements}

Financial support from NSF grants ERC NanotechnologyEnabled Water Treatment Center 1449500, CHE-0748913, DMR PREM-1205302, and USDA 2014-38422-22078 are gratefully acknowledged. We thank Dr Gardea-Torresdey research group for their kind assistance with the zeta potential experiments.

\section{References}

1 D. Elliott, P. Biller, A. Ross, A. J. Schmidt and S. B. Jones, Bioresour. Technol., 2015, 178, 147-156.

2 I. S. Goldstein, Organic chemicals from biomass, CRC Press, 2018.

3 A. Raheem, W. W. Azlina, Y. T. Yap, M. K. Danquah and R. Harun, Renewable Sustainable Energy Rev., 2015, 49, 990999.

4 N. A. Mostafa, A. A. Farag, H. M. Abo-dief and A. M. Tayeb, Arabian J. Chem., 2018, 11, 546-553.

5 A. Oasmaavan, B. de Beld, P. Saari, D. C. Elliott and Y. Solantausta, Energy Fuels, 2015, 29, 2471-2484.

6 S. K. Sharma, I. M. Mishra, M. P. Sharma and J. S. Saini, Biomass, 1988, 17, 251-263.

7 M. Patel and A. Kumar, Renewable Sustainable Energy Rev., 2016, 58, 1293-1307.

$8 \mathrm{H}$. Hu, B. Jiang, J. Zhang and X. Chen, RSC Adv., 2015, 5, 104769-104778.

9 K. R. Saravanan and N. Kalaiselvi, Carbon, 2015, 81, 43-53.

10 M. A. Ahsan, M. T. Islam, C. Hernandez, H. Kim, Y. Lin, M. L. Curry, J. Gardea-Torresdey and J. C. Noveron, J. Environ. Chem. Eng., 2018, 6, 4215-4225.

11 Q. Li, X. Tang, Y. Sun, Y. Wang, Y. Long, J. Jiang and H. Xu, RSC Adv., 2015, 5, 25337-25347.

12 J. W. C. Chen, Biotechnol. Adv., 20019, 27, 195-226.

13 Y. Cheng, C. Yang, H. He, G. Zeng, K. Zhao and Z. Yan, J. Environ. Eng., 2015, 142, C4015001.

14 H. J. He, Z. H. Xiang, X. J. Chen, H. Chen, H. Huang, M. Wen and C. P. Yang, J. Environ. Sci. Technol., 2018, 15, 1491-1500.

$15 \mathrm{~S} . \mathrm{Wu}, \mathrm{H}$. He, X. Inthapanya, C. Yang, L. Lu, G. Zeng and Z. Han, Environ. Sci. Pollut. Res., 2017, 24, 16560-16577.

16 S. Fan, Y. Wang, Y. Li, J. Tang, Z. Wang, J. Tang and K. Hu, RSC Adv., 2017, 7, 7576-7590.

17 R. K. Gautam, A. Mudhoo, G. Lofrano and M. C. Chattopadhyaya, J. Environ. Chem. Eng., 2014, 2, 239259.

18 J. Liu, S. N. Gosling, M. Kummu, M. Flörke, S. Pfister, N. Hanasaki, Y. Wada, X. Zhang, C. J. Zheng and T. Alcamo, Earth's Future, 2017, 5, 545-559.

19 Y. Shevah, in Water Challenges and Solutions on a Global Scale ACS Symposium Series 1206, American Chemical Society, Washington, DC, 2015, pp. 185-219.

20 Y. Jia Ren, A. Li Zhang, R. Feng, Y. Zhang and X. Bu, Cryst. Growth Des., 2016, 16, 5593-5597.

21 T. Ohe, T. Watanabe and K. Wakabayashi, J. Hazard. Mater., 2004, 567, 109-149. 
22 Environmental Protection Agency, Publication No. EPA-600/280-056, OH: Environmental Protection Agency, Columbus, 1980.

23 L. Ji, W. Chen, L. Duan and D. Zhu, Environ. Sci. Technol., 2009, 43, 2322-2327.

24 M. K. Purkait, S. DasGupta and S. De, Sep. Purif. Technol., 2004, 37, 81-92.

25 M. Yusuf, F. M. Elfghi, S. A. Zaidi, E. C. Abdullah and M. A. Khan, $R S C A d v$. , 2015, 5, 50392-50420.

26 M. T. Islam, N. Dominguez, M. A. Ahsan, H. DominguezCisneros, P. Zuniga, P. J. Alvarez and J. C. Noveron, J. Environ. Chem. Eng., 2017, 5, 4185-4193.

27 M. T. Islam, J. E. Padilla, N. Dominguez, D. C. Alvarado, M. S. Alam, P. Cooke, M. M. J. Tecklenburg and J. C. Noveron, RSC Adv., 2016, 6, 91185-91191.

28 M. T. Islam, R. Saenz-Arana, H. Wang, R. Bernal and J. C. Noveron, New J. Chem., 2018, 42, 6472-6478.

29 M. T. Islam, H. Jing, T. Yang, E. Zubia, A. G. Goos, R. A. Bernal, C. E. Botez, M. Narayan, C. K. Candace and J. C. Noveron, J. Environ. Chem. Eng., 2018, 6, 3827-3836.

30 R. K. Upadhyay, N. Soin and S. S. Roy, RSC Adv., 2014, 4, 3823-3851.

31 J. E Padilla, J. Melendez, L. A. Barrera, Y. Wu, K. Ventura, J. M. Veleta, M. T. Islam, C. A. Chavez, S. K. Katla, D. Villagrán and J. C. Noveron, J. Environ. Chem. Eng., 2018, 6, 1027-1032.

32 V. Homem and L. Santos, J. Environ. Manage., 2011, 92, 2304-2347.

33 J. Anwar, U. Shafique, Waheed-uz-Zaman, M. Salman, Z. Hussain, M. Saleem, N. Shahid, S. Mahboob, S. Ghafoor, M. Akram and R. Rehman, Green Chem. Lett. Rev., 2010, 3, 239-243.

34 B. Hameed, A. Din and A. Ahmad, J. Hazard. Mater., 2007, 141, 819-825.

35 T. Räisänen and D. Athanassiadis, Basic chemical composition of the biomass components of pine, spruce and birch, 2013.

36 M. T. Islam, C. Hernandez, M. A. Ahsan, A. Pardo, H. Wang and J. C. Noveron, J. Environ. Chem. Eng., 2017, 5, 5270-5279.

37 A. H. M. G. Hyder, S. A. Begum and N. O. Egiebor, J. Environ. Chem. Eng., 2015, 3, 1329-1336.

38 M. T. Yagub, T. K. Sen and M. Ang, Environ. Earth Sci., 2014, 71, 1507-1519.

39 M. A. Pimenta, G. Dresselhaus, M. S. Dresselhaus, L. G. Cancado, A. Jorio and R. Saito, Phys. Chem. Chem. Phys., 2007, 9, 1276-1291.

40 J. Ye, J. Zang, Z. Tian, M. Zheng and Q. Dong, J. Mater. Chem. A., 2016, 4, 13223-13227.

41 J. Ruan, T. Yuan, Y. Pang, S. Luo, C. Peng, J. Yang and S. Zheng, Carbon, 2018, 126, 9-16.

42 L. Qie, W. Chen, Z. Wang, Q. Shao, X. Li, L. X. Yuan, X. Hu, W. Zhang and Y. Huang, Adv. Mater., 2012, 24, 2047-2050.

43 E. M. Deemer, P. K. Paul, F. S. Manciu, C. E. Botez, D. R. Hodges, Z. Landis, T. Akter, E. Castro and R. R. Chianelli, Mater. Sci. Eng., B, 2017, 224, 150-157.
44 Q. Jiang, Z. Zhang, S. Yin, Z. Guo, S. Wang and C. Feng, Appl. Surf. Sci., 2016, 379, 73-82.

45 D. G. Castner, K. Hinds and D. W. Grainger, Langmuir, 1996, 12, 5083-5086.

46 S. A. Wohlgemuth, F. Vilela, M. M. Titirici and M. Antonietti, Green Chem., 2012, 14, 741-749.

47 Z. D. Hood, S. P. Adhikari, Y. Li, A. K. Naskar, L. Figueroa-Cosme, Y. Xia, M. Chi, M. W. Wright, A. Lachgar and M. P. Paranthaman, Chem. Select, 2017, 2, 4975-4982.

48 D. G. Castner, K. Hinds and D. W. Grainger, Langmuir, 1996, 12, 5083-5086.

49 M. I. Khan, T. K. Min, K. Azizli, S. Sufian, H. Ullah and Z. Man, RSC Adv., 2015, 5, 61410-61420.

50 Y. Gao, Y. Li, L. Zhang, H. Huang, J. Hu, S. M. Shah and X. Su, J. Colloid Interface Sci., 2012, 368, 540-546.

51 T. K. Sen, S. Afroze and H. M. Ang, Water, Air, Soil Pollut., 2011, 218, 499-515.

52 M. Mohammad, S. Maitra, N. Ahmad, A. Bustam, T. K. Sen and B. K. Dutta, J. Hazard. Mater., 2010, 179, 363-372.

53 Y. Yao, F. Xu, M. Chen, Z. Xu and Z. Zhu, Bioresour. Technol., 2010, 101, 3040-3046.

54 D. K. Singh, S. Mohan, V. Kumar and S. H. Hasan, RSC Adv., 2016, 6, 1218-1230.

55 Z. A. Jamiu, T. A. Saleh and S. A. Ali, $R S C A d v$. , 2015, 5, 4222242232.

56 S. Fan, Y. Wang, Y. Li, J. Tang, Z. Wang, J. Tang, X. Li and K. Hu, RSC Adv., 2017, 7, 7576-7590.

57 J. Shu, S. Cheng, H. Xia, L. Zhang, J. Peng, C. Li and S. Zhang, RSC Adv., 2017, 7, 14395-14405.

58 M. T. Islam, R. Saenz-Arana, C. Hernandez, T. Guinto, M. A. Ahsan, D. T. Bragg, H. Wang, B. Alvarado-Tenorio and J. C. Noveron, J. Environ. Chem. Eng., 2018, 6, 3070-3082.

59 T. Liu, Y. Li, Q. Du, J. Sun, Y. Jiao, G. Yang, Z. Wang, Y. Xia, W. Zhang, K. Wang and H. Zhu, Colloids Surf., B, 2012, 90, 197-203.

60 M. A. Ahsan, S. K. Katla, M. T. Islam, J. A. HernandezViezcas, L. M. Martinez, C. A. Díaz-Moreno, J. Lopez, S. R. Singamaneni, J. Banuelos, J. Gardea-Torresdey and J. C. Noveron, Environmental Technology \& Innovation, 2018, 11, 23-40.

61 P. Liao, Z. Zhan, J. Dai, X. Wu, W. Zhang, K. Wang and S. Yuan, Chem. Eng. J., 2013, 228, 496-505.

62 L. Zhang, X. Song, X. Liu, L. Yang, F. Pan and J. Lv, J. Chem. Eng., 2011, 178, 26-33.

63 M. A. Ahsan, M. T. Islam, C. Hernandez, E. Castro, S. K. Katla, H. Kim, Y. Lin, M. L. Curry, J. GardeaTorresdey and J. C. Noveron, J. Environ. Chem. Eng., 2018, 6, 4329-4338.

64 J. Jin, T. Feng, Y. Ma, W. Wang, Y. Wang, Q. Zhou and A. Li, Chemosphere, 2017, 185, 563-573. 